\title{
“OBJETOS PERFORADOS”, ASOCIACIONES SIMBÓLICAS Y REDES DE CIRCULACIÓN: REFLEXIONES SOBRE LAS FORMAS DE INTERCAMBIO EN EL PERIODO FORMATIVO (1500 AC-500 DC) DEL DESIERTO DE ATACAMA, NORTE DE CHILE
}

\author{
"PERFORATED OBJECTS”, SYMBOLIC ASSOCIATIONS AND CIRCULATION \\ NETWORKS: REFLECTIONS ON THE FORMS OF EXCHANGE IN THE \\ FORMATIVE PERIOD (1500 BC-500 AD) OF THE ATACAMA DESERT, \\ NORTHERN CHILE
}

Catalina Soto Rodríguez ${ }^{1}$

\begin{abstract}
Los objetos perforados son parte de los elementos que dan cuenta de actividades de intercambio en el Desierto de Atacama, y de manera más extendida en el área Centro-Sur Andina. Esto se evidencia en que las materias primas que le dan soporte a dichos objetos provienen de regiones diversas y distantes a los contextos donde han sido halladas. Siguiendo un análisis tipológico centrado en aspectos morfo-funcionales y la identificación de materias primas de conjuntos de objetos perforados provenientes de diferentes sitios del periodo Formativo (1500 AC-500 DC) ubicados en las áreas de Quillagua (Calate CH-2 y CH-3), Loa Medio (Talabre 26, Chorrillos, Topater) y Salar de Atacama (Tulán 54), se ha constatado que la mayoría han sido fabricadas en conchas de la costa Pacífica y el Noroeste argentino (NOA), seguidas de piezas de mineral de cobre obtenidas de fuentes locales. Estos lugares de origen, algunos bastante lejanos, nos permiten plantear hipótesis y reflexiones respecto a las formas en las que los objetos perforados fueron intercambiados considerando su estatus simbólico y social en sus contextos de depositación. Se piensa que esto constituye un avance en la evaluación de cómo estos objetos contribuyeron a construir y negociar identidades incorporadas en los cuerpos y extendidas en el paisaje y en el territorio.
\end{abstract}

Palabras claves: objetos perforados, cuentas de collar, intercambio, periodo Formativo, Desierto de Atacama.

Perforated objects are part of the elements that illustrate the exchange activities in the Atacama Desert, and in the SouthCentral Andes area more widely. This can be noted in the raw materials that support those objects and which come from diverse regions, far from the contexts where they have been found. Through a typological analysis focused on the morphofunctional aspects and on the identifcation of raw materials of sets of perforated objects from different sites of the Formative period (1500 BC-500 AC) in the areas of Quillagua (Calate CH-2 y CH-3), Loa Medio (Talabre 26, Chorrillos, Topater) and Salar de Atacama (Tulan 54), it has been verified that most of them were manufactured in shells from the Pacific coast and the Argentine Northwest (ANW), followed by copper ore pieces obtained from local sources. These places of origin, some of them very far from the sites, allow us to hypothesize and reflect on the ways the perforated objects were exchanged, considering their symbolic and social status in their deposit contexts. It is believed that this constitutes an advancement in the evaluation of the way these objects contribute to the construction and negotiation of embodied identities that also extend into the landscape and the territory.

Key words: Perforated objects, necklace beads, exchange, Formative period, Atacama Desert.

Los objetos perforados son artefactos que en la bibliografía arqueológica han sido denominados cuentas de collar, chaquiras u objetos misceláneos. Desde hace algún tiempo he reflexionado acerca del rol social de estos objetos en el Desierto de Atacama por medio de la teorización, análisis e interpretación de su potencial simbólico. A través de una propuesta tipológica (Soto 2006) se han estudiado las cadenas de producción del artefacto, y gracias a la identificación de ciertas materias primas se ha explorado su significación histórica a través de fuentes etnohistóricas y etnográficas andinas (Soto 2009, 2015). También se ha detallado su significado

\footnotetext{
${ }^{1}$ Centro de Estudios Latinoamericanos (CECLA), Universidad de Chile, Santiago, Chile. cata.sotorodriguez@ gmail.com
}

Recibido: marzo 2018. Aceptado: enero 2019.

http://dx.doi.org/10.4067/S0717-73562019005001301. Publicado en línea: 12-junio-2019. 
relacional y contextual al considerar los diferentes depósitos estratigráficos y algunos contextos regionales relevantes, concluyendo que sus usos se relacionan con funciones altamente simbólicas donde sus cualidades visuales son fundamentales (Soto 2015).

Todas estas interpretaciones se han articulado con el crucial momento al cual se atribuyen los sitios y los conjuntos analizados: el periodo Formativo. Este periodo en el Desierto de Atacama se ha definido como la consolidación de transformaciones acontecidas en el periodo Arcaico Tardío (3500-1500 AC), tales como cambios en la organización social de varios grupos en diferentes lugares de los Andes, adecuando sus patrones residenciales y movilidad a nuevas actividades productivas como el pastoreo y la silvicultura. Destacan entre sus particularidades, la aparición de cementerios y la monumentalidad de los sitios ceremoniales, espacios de congregación social en los que, como algunos autores proponen, se negociarían las relaciones sociales entre linajes emergentes y entre estos y las deidades en un contexto de transformaciones e inestabilidades (Núñez et al. 2017). Este es el momento en el que se introducen nuevas tecnologías que pronto tienen un gran impacto en la forma de construir las identidades socio-culturales, los límites sociales, así como en la forma de organizar el tiempo y el espacio. Si bien la producción de objetos perforados y la lapidaria como tecnología fue iniciada en el periodo anterior, en este se observa una intensificación en la producción visible en el aumento en el número de piezas en los sitios en general, el hallazgo de contextos de producción y un mayor número de piezas depositadas en contextos fúnebres y ceremoniales.

En consecuencia, los objetos perforados son un conjunto de materiales que presentan un importante potencial para la identificación de procesos de intercambio interregional, a lo que se suman las sugerentes asociaciones contextuales en que estos se presentan en los sitios arqueológicos. Este estudio en particular propone una evaluación de los objetos perforados como objetos circulantes, en conjunto con una revisión de las propuestas sobre el periodo Formativo y las diferentes interpretaciones sobre las formas de intercambio andinas, con la finalidad de profundizar la definición histórica de los desarrollos culturales de este periodo en los Andes Centro-sur.

El área de estudio en que nos situamos es el Desierto de Atacama (II región, Chile), una región perteneciente a la subárea Circumpuneña en los Andes Centro-sur. Ubicada en la vertiente occidental de la cordillera de los Andes es una zona cuya topografía se caracteriza por planos más o menos inclinados (depresión intermedia), flanqueada de norte a sur por cordones montañosos que definen los circuitos de los escasos cursos de agua, siendo solo uno de ellos el que cruza el territorio por completo, el río Loa. El clima se caracteriza por su escasa pluviosidad, con lluvias estivales (noviembre a marzo) en las tierras altas de Los Andes sobre los $2000 \mathrm{msm}$, lo que sumado a los aspectos latitudinales y altitudinales lo convierten en un espacio con recursos circunscritos a quebradas y concentrados en los lugares donde estas desaguan, como oasis y salares. Los sitios arqueológicos de donde proviene el conjunto analizado se ubican en torno a algunos de los principales oasis del río Loa (Quillagua, Calama y Chiu Chiu), en sitios cercanos al Salar de Atacama y en vías de conexión entre estos espacios (Figura 1).

\section{Objetos Perforados: Una Definición Conceptual}

Cuentas de collar o chaquiras, son los apelativos más comunes aplicados a artefactos que tienen una perforación, facturados en materias primas resistentes -de origen animal, vegetal y mineral- cuya característica principal es que son perforados con una o más horadaciones para ser colgados o hilados. A veces estos se encuentran trabajados por medio de técnicas como el tallado y el pulido, otras veces se dejan expuestas las texturas naturales de los materiales. Suelen ser parte, junto a otros elementos, de composiciones mayores de objetos; así, su consumación artefactual se concreta cuando son incrustados en madera, colgados o cosidos en telas o hilados para ser utilizados como collares, pulseras o diademas (Soto 2006, 2010, 2015). Sin duda, los objetos perforados son objetos que operan como un dispositivo visual, por lo que sus cualidades de color, forma y textura son fundamentales a la hora de constituirse en elementos con significado social (Ingold 2007). Desde hace algún tiempo se viene utilizando el concepto de "objeto perforado" como uno que no encasilla una interpretación funcional, debido a que objetos idénticos pueden ser utilizados como componentes de artefactos que no se asemejan en nada a un objeto de uso corporal, como su incrustación en vasos de madera.

Respecto al conjunto analizado, se han identificado piezas utilizadas en conjuntos (collares) y colgantes de remate o incorporados en el tejido de otros objetos, efectuados en materias primas minerales (crisocola, turquesa, malaquita), líticas, concha, hueso y semillas, acompañando el cuerpo de individuos de distinto sexo, además de depositados dispersos en contextos interpretados de carácter ceremonial, asociados a caminos y sitios con arquitectura monumental de piedra (Soto 2015). Vale la pena detenernos en los usos de estos artefactos en algunas de las configuraciones observadas (Figura 2).

En algunos casos se observan como artefactos únicos y en otros como parte de objetos que participan de rituales y ceremonias, contextos de alto significado político en tanto espacios de negociación entre seres 


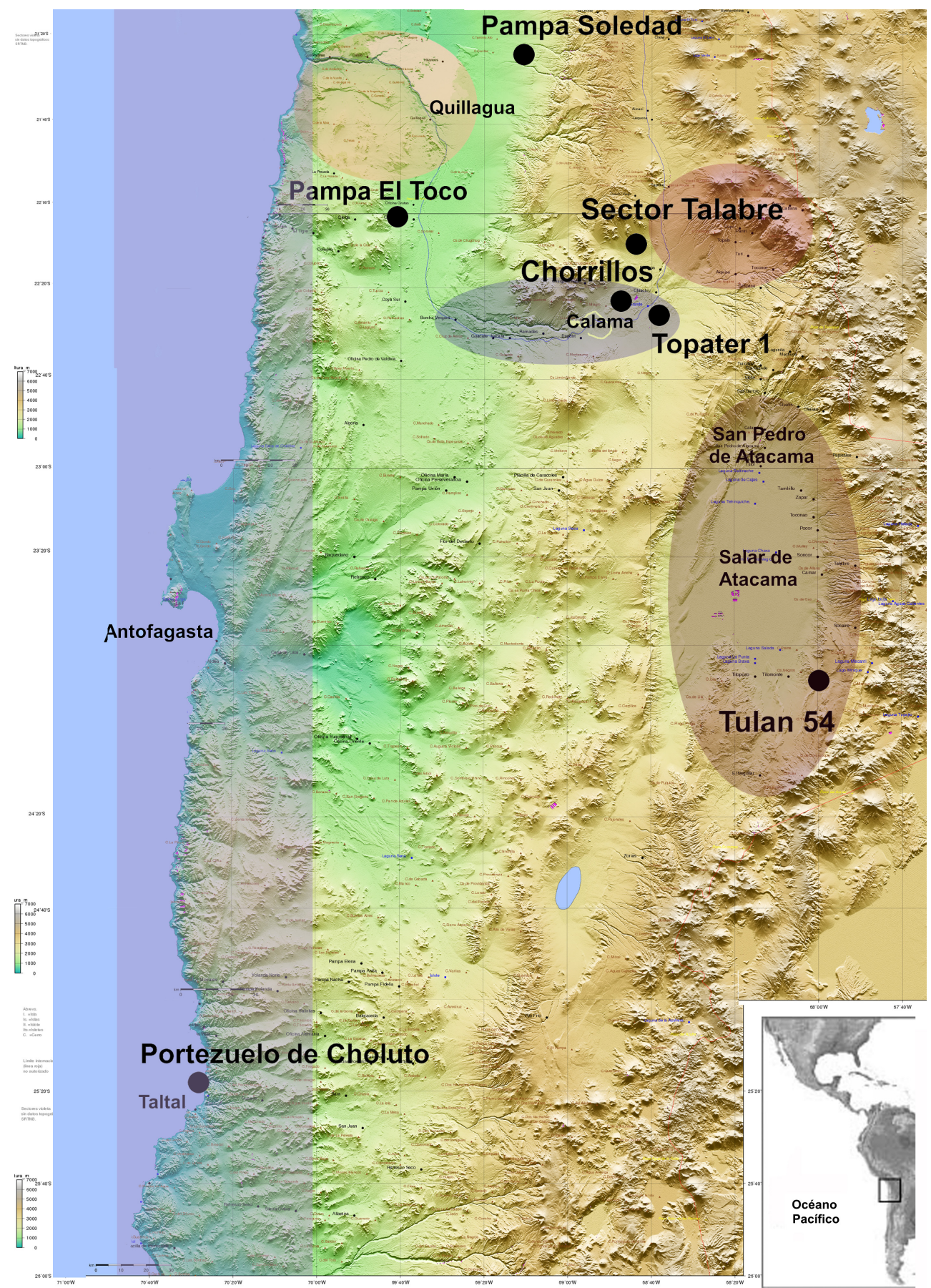

Figura 1. Área de estudio y sitios mencionados en el texto.

Study area and sites mentioned in the article. 

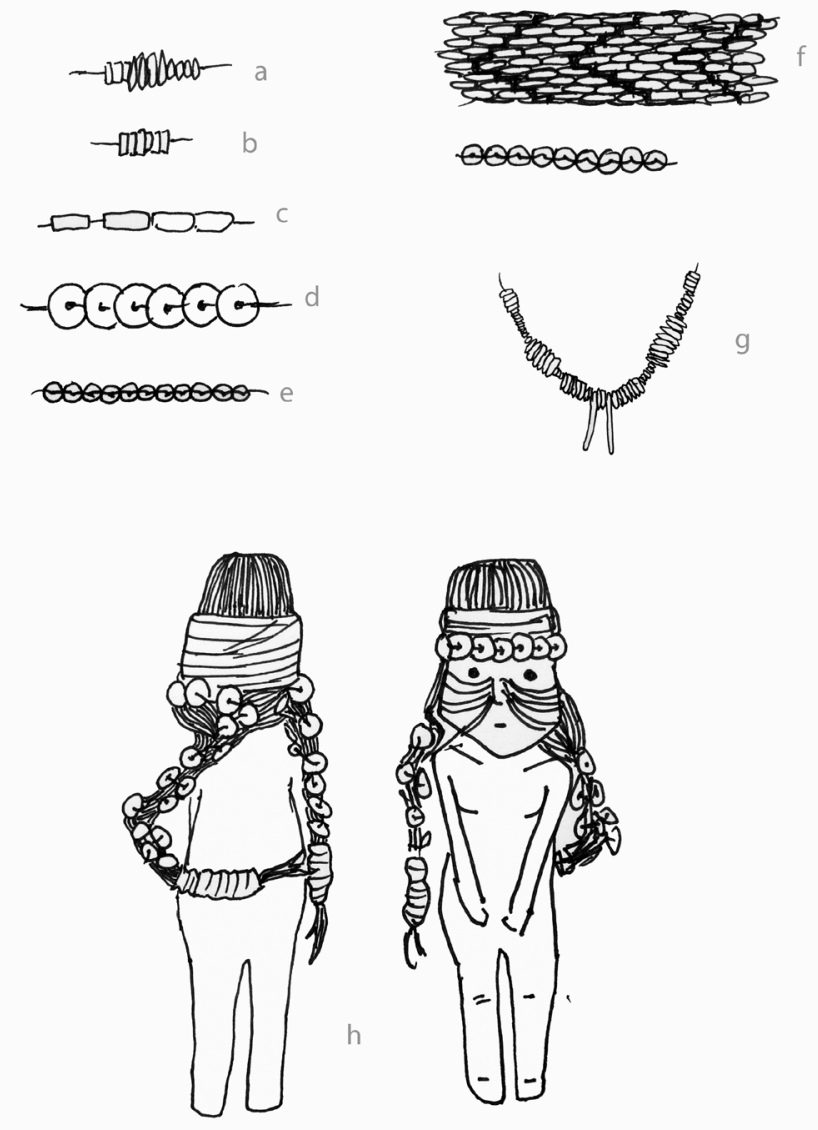

Figura 2. Disposición de tipos de conjuntos de objetos perforados en nuestra muestra de estudio. (a) vista sección de diferentes tamaños, (b) vista sección mismo tamaño, (c) tubular, (d) escamado; (e) tejido, (f) huincha tejida, Topater, (g) collar o pulsera, Choluto, (h) figura antropomorfa con cuentas dispuestas como escamas a modo de diadema y tejidas entre el pelo del trenzado, Topater.

Ensemble of the types of sets of perforated objects in our study sample. (a) Different sizes section; (b) same size section; $(c)$ tubular; $(d)$ scaly; $(e)$ weave; $(f)$ weaved band, Topater; $(g)$ necklace or bracelet, Choluto; $(h)$ anthropomorphic figure with beads arranged like scales as diadem and weaved between the hair of the braid, Topater.

humanos, o entre seres humanos y entes divinos. En otros, su función es ornamental significando en el contexto del cuerpo y en la construcción de identidades individuales y/o grupales. Es decir, en lo que algunos autores denominan embodiment, el cual se refiere a las prácticas temporales y definitivas de 'incorporación' u ornamentación del cuerpo (p.ej., vestimentas, tatuajes, pintura, deformación craneana (Joyce 2005). El cuerpo se presenta como una especie de soporte en donde técnicas del cuerpo, vestimenta u otros objetos incorporados refuerzan su rol de expresión y comunicación (Joyce 2005; Mauss 1973; Soto 2010; Waskul y Vannini 2006). En ambas situaciones, como parte del embodiment o como objeto ritual, los objetos perforados constituyen elementos que componen artefactos con un alto valor simbólico en situaciones de flujo y movimiento de los cuerpos que los movilizan. Pero también, al ser depositados en lugares cuya referencia espacial es uno de sus destinos finales, se convierten en elementos que se vinculan al paisaje en tanto espacio construido, manteniendo un flujo entre sus características materiales y artefactuales, los individuos, sus cuerpos y el paisaje. Debido a ello, la denominación genérica de objetos perforados permite englobar todas las funciones recién descritas.

\section{Propuestas Sobre el Intercambio desde los Andes Centro-Sur}

Una las propuestas clásicas sobre varios aspectos de la vida económica en los Andes, sin duda, es la del etnohistoriador John Murra (1975). A través de la lectura y análisis de la Visita hecha a la Provincia de Chucuito, realizada a la etnia Lupaca del lago Titicaca por Garci Diez de San Miguel en el año 1567, Murra propone una ocupación del espacio en archipiélagos 
verticales (parches de recursos definidos por la altitud) a través de colonias establecidas por grupos de tierras altas que funcionarían como cabeceras en una jerarquía de asentamientos, y cuyo objetivo fundamental sería la optimización en la explotación de recursos distantes. Dicho modelo de alguna manera tiene una correlación con el modelo de control de elite según el cual existiría un control por parte de un grupo dominante de las rutas y de los objetos intercambiados, así como de la especialización y el excedente, pues en la integración de todas estas esferas es en donde se generaría valor, legitimación y prestigio personal de la autoridad (Blanton et al. 1996). El modelo de Murra (1975), fue durante mucho tiempo complementado con otras interpretaciones que incorporaban esta estrategia con actividades como el caravaneo, propio del altiplano y la puna del sur andino. Las caravanas de llamas se consideraron los principales agentes de movimiento de bienes a través de diferentes regiones como un tráfico especializado dentro de economías corporativas y autosuficientes, con circuitos estacionales giratorios (Browman 1980; Núñez y Dillehay 1979).

Recientemente, en una exhaustiva revisión acerca del rol de la circulación de objetos en la constitución de la sociedad en los Andes Centro-sur, Axel Nielsen (2013:410) hace hincapié en que el intercambio nos remite a la construcción de un espacio social, cuyo funcionamiento se concreta a través de dos tipos de transporte. El primero reconocido es el tráfico especializado, representado más claramente por el caravaneo, y el segundo, el tráfico incorporado, el que ocurriría en espacios sociales a los que los grupos recurren con fines logísticos específicos. En el mismo texto compilatorio Charles Stanish (2013) advierte de la posible existencia de intercambios mercantiles en ferias de trueques itinerantes durante el periodo Inka, situación absolutamente plausible en eventos sociales como fiestas, rituales y peregrinaciones. Esta idea ya había sido sugerida por Núñez y Dillehay (1995:107) en su modelo de Movilidad Giratoria, quienes consideraron la existencia de ferias móviles de reunión de caravanas durante el periodo Tiwanaku que en ciertos lugares habrían frustrado incluso intentos urbanísticos. Esta proposición poco o nada ha sido retomada o trabajada por las investigaciones posteriores.

La propuesta de Nielsen (2013) sobre intercambio oportunístico rebate por un lado la existencia de un sistema de intercambio monolítico, monopolizado por agentes de tierras altas y la preeminencia de la caravana como principal agente de movimiento de bienes. Asímismo, Pimentel (2013) y Pimentel et al. (2011), señalan que no solo se están transportando objetos con caravanas, sino que también sujetos a pie con rutas propias estarían ingresando al desierto desde la costa con sus propios objetivos.
Una visión interesante es la que propone Lazzari (1999) al poner de relieve que todo intercambio, más que demostrar la armonía andina, es una negociación tensa y conflictiva que acentúa la relación de deuda mutua. En esta negociación se estaría concretando la construcción de un espacio social ampliado, en donde los objetos extenderían los límites del grupo más allá de su propia presencia, haciendo palpable la interacción (Lazzari 2005:149). Esto no solo resultaría relevante en términos simbólicos y en la construcción y legitimación de identidades y relaciones sociales interétnicas e intragrupales. La concreción de las negociaciones y el intercambio activan la economía, tanto de los grupos que producen excedentes como de aquéllos que son núcleos receptores y redistribuidores. Un ejemplo de esto es desarrollado por Bandy (2004) quien contrasta información medioambiental con el auge y caída de los sitios de Chiripa (periodo Formativo) y Tiwanaku (periodo Medio) en el sector sur del Lago Titicaca, donde un cambio notable en los niveles del lago permitió la modificación de la ruta longitudinal trasladando su eje unos $13 \mathrm{~km}$ más al sur, quedando con ello fuera el primer sitio de la ruta, potenciando así su abandono.

A partir de las interpretaciones antes expuestas, otro de los temas tratados en referencia al intercambio son los lugares que funcionaron como nodos (Llagostera 1996) y los espacios internodales, como fuentes de valiosa información sobre quiénes y cómo (Nielsen 2006; Pimentel 2013). Así se ha podido documentar entre otras cosas que el tráfico no fue una actividad solo masculina (Torres-Rouff et al. 2012). A partir de estas mismas exploraciones se ha desarrollado la idea de que existirían esferas de intercambio diferenciadas, al menos de manera clara a partir del periodo Medio: una esfera restringida que incluiría sustancias sicotrópicas y herramientas para su consumo, ciertas armas que pueden haber servido como emblemas, textiles finos, tocados y una variedad de ornamentos, hechos seguramente de oro y plata; y una esfera no restringida en donde se incluiría cerámica, minerales de cobre, líticos, maderas para hacer artefactos, plumas, textiles menos sofisticados, conchas terrestres y marinas, y diferentes tipos de cultivos (coca, maíz, chañar, quinua, tubérculos) y sal (adaptación de Nielsen 2013:414).

En un trabajo anterior referido específicamente a la fabricación y depositación de valvas y artefactos de concha en los sitios Tulán 54, Tulán 85 y Tulán 122 , algunos de ellos objetos perforados, se sugiere que estos participarían de dos sistemas simbólicos: uno ritual con objetos ubicados en contextos ceremoniales y fúnebres en forma de collares y otro cotidiano, o no ritual, con cuentas dispersas que probablemente podrían participar de circuitos de intercambio (Soto 2009:104). Estas ideas pueden ser 
entroncadas con las propuestas recién expuestas, tanto en relación con los objetos que son subjetivados al punto que salen del circuito del intercambio, en este caso a través de su depósito final o depositación en contextos rituales, y la posibilidad de que algunos de estos objetos sean objetivados e intercambiados de formas semejantes a lo que conocemos como mercancías.

Según Gallardo (2013:599), en una revisita de la Visita de Garci Diez indica que el mismo Murra en un texto de 1964, anterior al clásicamente citado, admite el trueque como una estrategia de intercambio diferente a los bienes obtenidos por colonización. A través del análisis y triangulación de distintas fuentes etnográficas y etnohistóricas, Gallardo rebate la inexistencia de mercado entre los Lupaca del siglo XVI, señalando que los intercambios no se deberían a la escasez de productos alimenticios y que existieron categorías especiales de objetos destinados al intercambio económico comunal en ferias y para el comercio de larga distancia, mientras que las colonias verticales serían parte de una estrategia autonómica de grupos de líderes de mayor jerarquía (Gallardo 2013). Aunque para Gallardo (2013:609) "un intercambio económico era siempre una relación social cuya reproducción tenían que satisfacer las exigencias de las obligaciones reciprocitarias (ayni)".

Si bien estas modalidades de intercambio no han sido aceptadas para las áreas serranas y altiplánicas de Los Andes, Espinoza Soriano (1987) documenta a través de textos primarios prácticas mercantiles en épocas prehispánicas para la costa norte y central peruana siendo objetivados productos como la coca, el ají y Spondylus. No obstante, para periodos tempranos estas formas de intercambio no han sido exploradas, por considerarse que los objetos encontrados en contextos fúnebres, ceremoniales y rituales adquirirían una subjetivación asociada a lo religioso o lo político, siguiendo modelos como los que consideran que materiales exóticos y tecnologías especializadas se asocian a prácticas de prestigio (Hayden 1998; Peregrine 1991). Considero que esto también se relaciona con la gran influencia que han tenido algunos modelos clásicos sobre el intercambio que se centran justamente en esferas altamente controladas de intercambio político y ritual de tipo reciprocitario, y que describen muy bien cómo los objetos adquieren mayor poder de acuerdo con quiénes le han dado forma y de quiénes han sido sus usuarios, buscando las formas en que el poder se reproduce en sociedades precapitalistas (Malinowski 1986; Mauss 1979; Sahlins 1983a, 1983b).

En síntesis, parece ser que el modelo de la reciprocidad (Murra 1972, 1975) y la armonía (Núñez y Dillehay 1995), junto con el control y funcionamiento estatal observado a partir de datos etnohistóricos, ha mantenido cierto nivel de idealización respecto al intercambio más objetivado, observándose de manera predominante la circulación como producto de relaciones que procuran mantener lazos recíprocos de obligación y deuda a través del intercambio de dones en sociedades prehispánicas tardías y etnográficas (Platt 1987). Aun cuando Núñez y Dillehay (1995) y otros autores como Mayer (1982) dan cuenta de otras estrategias en las que los que intercambian no pretenden mantener relaciones a largo plazo, ni tampoco corresponde a intercambios controlados por elites, abriendo posibles intercambios que se relacionen o asemejen a las mercancías según su definición más clásica. A continuación, realizaremos una revisión teórico conceptual para luego analizar cómo funcionan estas teorías en la distribución de objetos perforados en el periodo Formativo del Desierto de Atacama.

\section{Algunos desarrollos teóricos generales: sujetos, objetos e intercambios}

Para problematizar los artículos intercambiados es necesario partir de que la cultura material es una categoría con múltiples funciones y significaciones sociales, que van más allá de la función original para la que muchos artefactos fueron fabricados. Los objetos son significativos en la vida social, pues propician y construyen, quizá de manera más efectiva cuando no los vemos (Miller 2005:5) lo que sucedería de manera constante y potente dada su intensa integración a la vida social (Olsen 2003). Es evidente que, en la producción de cualquier objeto, más aún de aquéllos que requieren de inversión de tiempo y conocimiento, se modela la organización social en tanto esta debe acomodarse a sus requerimientos de producción. Sin embargo, es importante tener en consideración que las acciones que generan valor agregado en los objetos no son la única forma en que estos colaboran en la construcción de los sujetos y sociedades, y además no necesariamente constituyen la forma más sustantiva en la que los objetos adquieren estatus social o se constituyen en mercancías con valores específicos (Appadurai 1991:21). Si bien esta idea es planteada siguiendo a Marx (1975) "la mercancía es un producto destinado principalmente al intercambio", para Appadurai (1991) este tipo de valoración surge no solo en sociedades capitalistas. Es interesante entonces señalar que entre la polaridad don y mercancía, existiría una gradiente de opciones que podemos ir explorando a partir de la definición extra de ambas formas, probablemente inexistentes en su estado puro.

Esto nos lleva a una reflexión en la que identificamos una separación epistémica actual entre las personas y el mundo exterior, como realidades de alguna manera dicotómicas, y la que aparentemente permitiría la existencia de objetos sobre los que no existirían valoraciones afectivo-simbólicas como es el 
caso de las mercancías en su más puro estado de fetiche. Varios autores trabajan el problema de la relación sujetoobjeto para pensar asuntos relativos a la cultura material (p.ej., Ingold 2012; Kopytoff 1991; Miller 2005; Olsen 2003; Thomas 1991) cuestionando la existencia de dicha relación más allá de lo operativo, pues entre sujeto y objeto existe un continuo en el que ambos se influyen construyendo a través de dicha interacción al individuo, la cultura material y gracias a ello materializando las instituciones y relaciones sociales. Ingold (2012:436437) argumenta a favor de la superación de la dicotomía por los motivos recién expuestos y porque además anulan la posible participación de entes no humanos y no artefactuales en la vida social. Por el contrario, Miller (2005:8), señala que la dicotomía es aplicable si concebimos al proceso que él denomina de objetivación. Dicho proceso operaría bajo el supuesto de que todo lo que creamos tiene el potencial de aparecer o convertirse en ajeno a nosotros, adquiriendo intereses (agencia) y trayectoria propios.

Tal como en otros aspectos discursivos e interpretativos, es común que sea señalada la imposibilidad de que las sociedades tradicionales hayan desarrollado formas de valoración semejantes a las occidentales. Es así como la categoría de don, como objeto de intercambio en sociedades tradicionales, se opone a la de mercancía, como parte del mecanismo de intercambio propio de sociedades occidentales/modernas. Esta dicotomización entre don y mercancía ha sido un constructo que ha pasado por alto las semejanzas y coincidencias entre las perspectivas que los autores han dado en sus definiciones de don y mercancía -Mauss y Marx (Appadurai 1991:27). Sin duda, el escrito fundamental de Appadurai (1991:24) es uno de los que comienza a advertir sobre las limitaciones de continuar aplicando esta distinción sin cuestionamientos, adhiriendo a la definición de que mercancía correspondería a cualquier cosa destinada al intercambio más allá de la existencia de algún tipo de dinero o moneda. Con ello el autor traslada el foco de la problemática hacia las formas de intercambio distinguiendo entre trueque y obsequios. Estas ideas son conciliadas con el modelo propuesto por Kopytoff (1991) en el mismo libro que Appadurai introduce, en donde se considera que ciertos objetos transitan en diferentes momentos de su biografía por procesos de objetivación y subjetivación, pasando por estados mercantiles (o de objetivación extrema) que no necesariamente los definen de por vida.

Thomas (1991) adhiere a la crítica de la oposición entre ambos conceptos, quitando con ello el velo idealista respecto a la posibilidad de utilizar don y mercancía como representantes unívocos de ciertos tipos de economías y de tipos de sociedades específicas, sobre todo porque además estas formas de valoración pueden darse de manera compleja e incluso "enmarañada" y confusa (entaglement). En este sentido para Thomas (1991:9) los objetos transitarían por diversas formas de apropiación y recontextualización según formas de valor y objetivación culturalmente específicas que, más allá de un tránsito biográfico como propone Kopytoff (1991), la condición de funcionar como don o mercancía correspondería más bien a cualidades potenciales constitutivas y contextuales asociadas a su carácter complejo (Thomas 1991).

Si bien no podemos considerar como aplicable de manera estricta la dicotomía entre dones y mercancías, ciertamente, nos ayudan a pensar el problema de los objetos que son intercambiados y circulantes, de aquéllos que salen o se desvían de estos circuitos para funcionar en las esferas político-rituales, y aquéllos que nunca entraron en las esferas del intercambio. Es decir, para pensar la amplia variedad de situaciones en las que los objetos son parte de las relaciones sociales, en un contexto relacional que se debe además a la diversidad de objetos que constituyen la cultura material y que por diferentes razones históricas se convierten en intercambiables. A partir de su experiencia en el estudio de materiales en el NOA, Lazzari (2005) propone el concepto de textura para explicar esta situación de interdependencia de los objetos con otros elementos y seres mostrándonos de manera concreta nuestra relación con el mundo.

Según Lazzari (2005:150) la circulación de objetos ilumina las muy diversas maneras de hacer las cosas, las personas y el espacio. Siguiendo esta idea, podemos pensar no solo en la forma que se dan estas prestaciones, sino sobre todo cómo los distintos grupos negociaron objetos y relaciones sociales que fueron constitutivas de los flujos de construcción de identidad, organización social y construcción ideológica, en toda la complejidad indivisible entre sujeto-objeto-espacio (Ingold 2003). El intercambio, desde la dimensión espacial, colaboraría también con procesos de regionalización (Giddens 1979 citado por Lazzari 1999:18) como un proceso de generación de identidades ampliadas en el espacio que son creados en función de intereses locales a través de la experiencia, como parte de un mundo que no es dado, sino vivido.

Citando a Bourdieu (1977), Lazzari (1999:25) propone que todos los intercambios son inseparablemente materiales y simbólicos, y debido a ello pueden convertirse en herramientas ideológicas poderosas. Es necesario entonces, incluir las formas de intercambio en un modelo interpretativo que considere las prácticas sociales de extensión, presencia y dominio espaciotemporal que se construyen y reproducen a través del movimiento de ciertos objetos (Lazari 1999:24), despojándonos de los supuestos que enmarcan nuestras interpretaciones en la polaridad del don y la mercancía. 
Para el caso analizado, proponemos que se trata de artefactos que tienen ciertas cualidades que los convierten en objetos con potencial de ser intercambiados en formas que cubren el amplio espectro de dones y mercancías, y no solo objetos que adquieren valor en el intercambio (Appadurai 1991) pues son objetos con un significado "enmarañado" (entaglement). Los materiales en los que están facturados tienen cualidades que les dan un potencial visual importante, pero sobre todo hay varios niveles de significación que le agregan valor: el origen de la materia prima, el trabajo de pulido y perforación, usos sobre el cuerpo como collares u otros ornamentos, o la incrustación o aplicación en artefactos de madera y textiles. Más complejos aún si pensamos en que en algunos casos los usuarios también pudieron agregar valores.

\section{Materiales y Métodos}

Para avanzar en una reflexión teórica y aplicada respecto al intercambio durante el periodo Formativo y el rol de los objetos perforados en estos procesos, se aplicó un análisis tipológico a alrededor de 8000 piezas registradas de los sitios templete Tulán 54 (Salar de Atacama), cementerio de Chorrillos (Calama), cementerio Topater (Calama) y de rutas del sector de Pampa Soledad (al norte de Quillagua) y Pampa Talabre (noroeste de Chiu Chiu) (Figura 1 y 3 ).

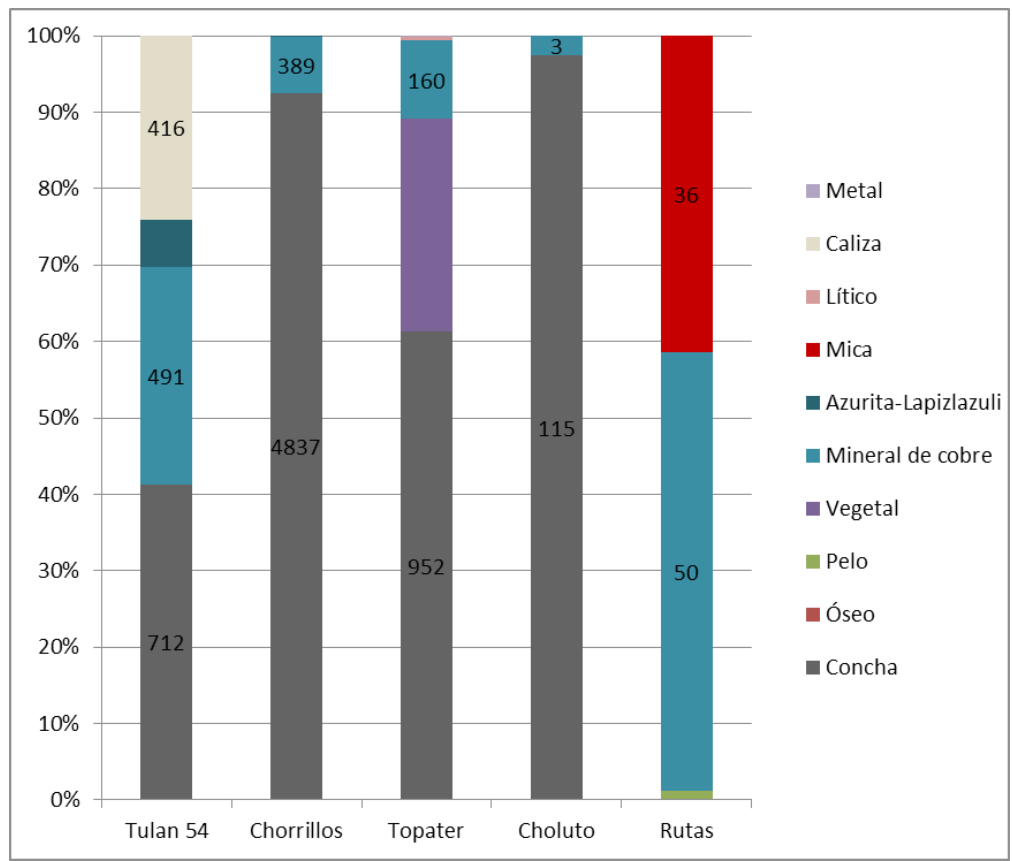

Figura 3. Gráfico de porcentaje de materia prima por contexto.

Percentage graph of raw material per context.

La caracterización del conjunto incluyó una tipología definida por características morfo-funcionales, tecnológicas y de materia prima, diferenciando formas, tamaño (medidas con pie de metro digital), colores, cantidad de perforaciones y forma de las mismas, además de huellas del pulido. La materia prima se identificó a ojo desnudo entre mineral y orgánico, y para diferenciar materias primas de colores blanquecino como piedra, óseo y concha a través del uso de lupa binocular. A partir de ello se completó la tipología propuesta por Soto $(2010,2009)$, diferenciando las piezas por forma (discoidal), tamaño (mínima $<3,9 \mathrm{~mm}$, pequeña 4 a $6 \mathrm{~mm}$, mediana 6.1 a $10 \mathrm{~mm}$ y grandes $>10 \mathrm{~mm}$ ) y materia prima. Para un panorama de la tipología de cuentas del periodo ver tipología en Figura 4.
Si bien identificar la especie entre los objetos perforados de concha es una tarea que en un nivel de mayor detalle requiere de técnicas de laboratorio, a través de la comparación de características físicas como la composición más o menos nacarada y como el grosor de la valva entre especies actuales recolectadas en el NOA y la costa Pacífica y las piezas analizadas, es posible discriminar su origen marino o terrestre. La densidad del ambiente marino genera valvas más gruesas. Así mismo, por asociación a contextos productivos y otras colecciones antes observadas hemos podido distinguir el uso como materia prima de especies del Pacífico como Argopecten purpuratus, Choromytilus chorus y 


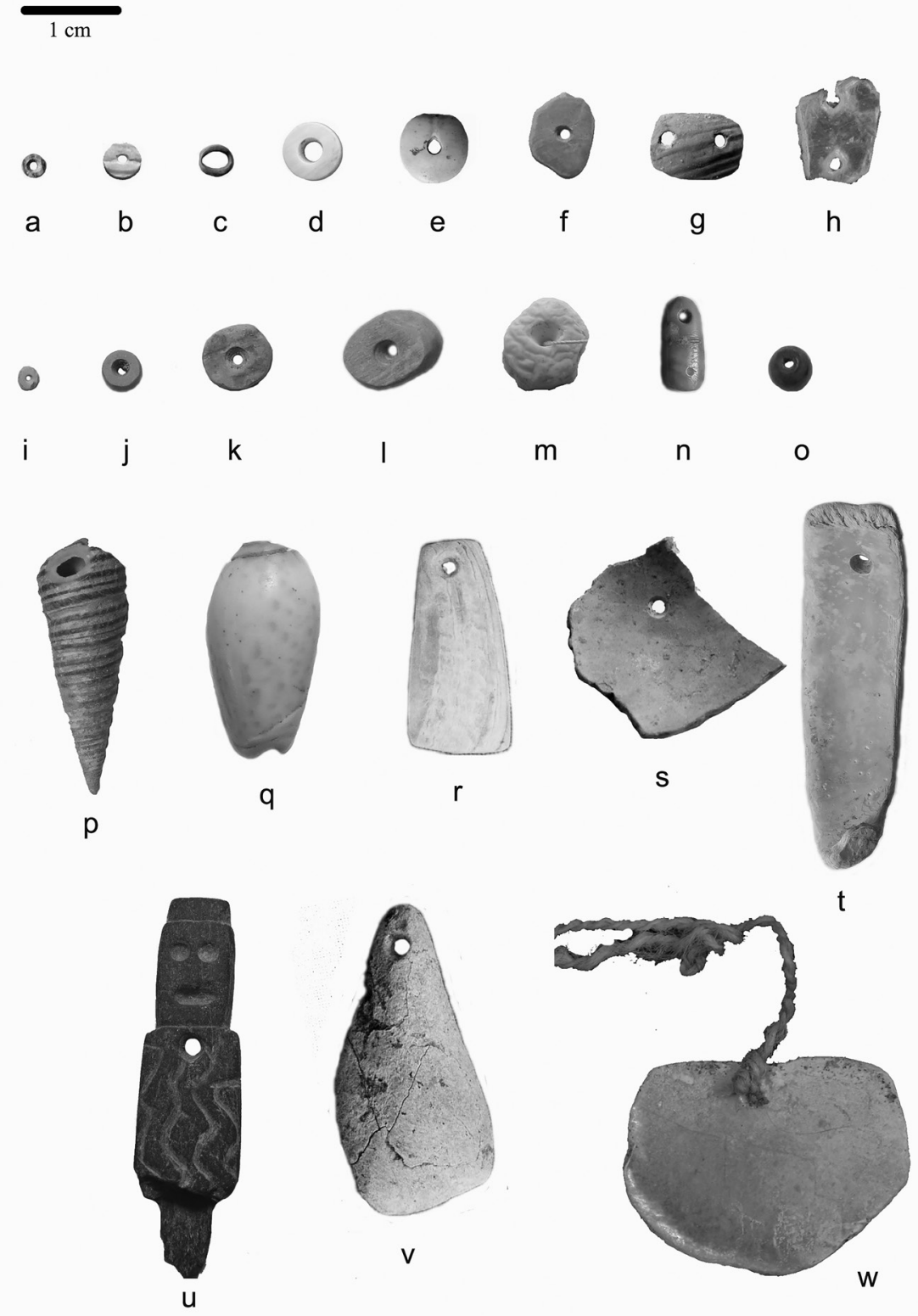

Figura 4. Tipología de objetos perforados del periodo Formativo (tomado de Soto 2015). Cuentas de concha: (a) discoidal mínima, (b) discoidal pequeña, (c) ápex de fissurelido, (d) discoidal mediana tipo 'arcaico', (e) discoidal plana con huellas de uso, (f) irregular con periostraco a la vista, (g) rectangular de Strophocheilus con doble perforación. (h) Cuenta de cristal de yeso con doble perforación. Cuentas de mineral de cobre: (i) discoidal mínima, (j) discoidal pequeña, (k) discoidal mediana, (l) discoidal de sección rectangular, (n) pendiente, (m) cuenta lítica de corteza; (o) semilla de 'achira'. Pendientes, (p) Turritela cingulata perforada, (q) Oliva peruviana sin ápex, (r) pendiente de Choromytilus chorus, (s, t) fragmento de Strophocheilus oblongus perforado, (u) pieza antropomorfa lítica, (v) trozo de mineral de cobre con perforación, (w) pendiente trapezoidal de cristal de yeso con amarra.

Typology of perforated objects from the Formative period (taken from Soto 2015). Shell beads: (a) minimum discoidal, (b) small discoidal, (c) apex of fissurellidae, (d) 'archaic'- type median discoidal, (e) flat discoidal with traces of use, (f) irregular with visible periostracum, $(g)$ rectangular Strophocheilus with double perforation. (h) Gypsum-glass bead with double perforation. Copper ore beads: (i) minimum discoidal, (j) small discoidal, $(k)$ median discoidal, $(l)$ rectangular section discoidal, $(n)$ earring, $(m)$ lithic bark bead; (o) 'achira' seed. Earrings, $(p)$ perforated Turritela cingulata, $(q)$ Peruvian olive without apex, $(r)$ Choromytilus chorus earring, $(s, t)$ Fragment of perforated Strophocheilus oblongus, $(u)$ lithic anthropomorphic piece, $(v)$ piece of copper ore with perforation, (w) gypsum-glass trapezoidal earring with tie. 
Concholepas concholepas (Soto y Power 2013; Soto et al. 2018) y del NOA como Strophocheilus oblongus (Soto 2009, 2015). En cuanto al mineral de cobre, se distingue a manera genérica, aunque es evidente que en el conjunto se presentan distintas calidades algunas de piedras semipreciosas azuladas como turquesa y malaquita. Se identifican también como piedras azules a las que podrían corresponder a azurita o lapislázuli.

La interpretación consideró aspectos cuantitativos en los sitios con mayores cantidades, y de orden cualitativo al ser comparados con los de menores volúmenes de material. Esto permitió también incorporar la información bibliográfica a veces poco detallada respecto a cantidades y características de los objetos perforados de otros sitios del periodo.

\section{Uso y Función de los Objetos Perforados en el Periodo Formativo del Desierto Atacameño}

Las investigaciones sobre el periodo Formativo han sido bastante prolíficas en interpretaciones sobre asentamientos con diversidad arquitectónica, cultura material variada y un nivel de conservación de materiales de calidad excepcional (Agüero 2005; Agüero et al. 2006; Castro et al. 2016; Sinclaire 2004). El periodo ha sido definido como un momento de creciente complejidad social en donde se observa la consolidación de procesos de especialización artesanal (Uribe 2006) e inicios de la vida pastoril (Cartajena 1994; Núñez et al. 2006b), inicios del proceso aldeano y la introducción del manejo y cultivo de especies vegetales domésticas documentado especialmente en los alrededores de San Pedro de Atacama al norte de Salar (Agüero 2005; Agüero y Uribe 2011), al sur de Salar en quebrada Tulán (Núñez et al. 2006b), en el alto Loa (Sinclaire 2004; Sinclaire et al. 1997) y Chiu Chiu en curso medio del Río Loa (Benavente 1981; Pollard 1971). Junto con ello, se ha considerado que la circulación de objetos, observada desde el periodo anterior de cazadores recolectores complejos o Arcaico tardío, se consolidaría adquiriendo especial relevancia en el proceso social local y macrorregional observable en una mayor diversidad y volumen de objetos no locales en los contextos del área asociado a un marcado ceremonialismo (Agüero et al. 2001; 2006; Núñez et al. 2006b; Núñez et al. 2017).

Respecto a la temporalidad, se han propuesto al menos tres momentos (Tabla 1). Uno inicial (ca. 1500AC$500 \mathrm{AC}$ ) con un énfasis más pastoril y con ocupaciones distribuidas en torno a quebradas con asentamientos efímeros y dispersos (Agüero y Uribe 2011), y durante el mismo momento un sitio ceremonial, Tulán 54, compuesto por arquitectura monumental y una serie de ofrendas de materialidades exóticas o tecnologías nuevas (Núñez et al. 2005; 2006a; 2006b). Luego (500 AC-200

Tabla 1. Sitios arqueológicos considerados en esta investigación con referencia a localidades, periodos y fechas. Tomado de Soto (2015:46 )

Archeological sites covered by this study with reference to localities, periods and dates. Taken from Soto (2015:46)

\begin{tabular}{|c|c|c|c|c|c|c|}
\hline Subregión & Localidad & Sitio & Contexto & Periodo & Fechados & Fuentes \\
\hline \multirow[t]{3}{*}{ Salar } & Peine & Tulán 54 & Basural & $\begin{array}{l}\text { Formativo } \\
\text { Temprano }\end{array}$ & $\begin{array}{l}3080 \pm 70 \text { AP } \\
2840 \pm 60 \text { AP }\end{array}$ & $\begin{array}{l}\text { Núñez et al. } \\
2005,2006\end{array}$ \\
\hline & & & $\begin{array}{l}\text { Depósito } \\
\text { Intramuro } \\
\text { (templete) }\end{array}$ & $\begin{array}{l}\text { Formativo } \\
\text { Temprano }\end{array}$ & $\begin{array}{l}2630+70 \text { AP } \\
2550+40 \text { AP }\end{array}$ & $\begin{array}{l}\text { Núñez et al. } \\
2005,2006\end{array}$ \\
\hline & & & $\begin{array}{l}\text { Estructuras } \\
\text { Extramuro } \\
\text { Norte }\end{array}$ & $\begin{array}{l}\text { Formativo } \\
\text { Temprano }\end{array}$ & $2740 \pm 70 \mathrm{AP}$ & $\begin{array}{l}\text { Núñez et al. } \\
2005,2006\end{array}$ \\
\hline Loa Medio & Calama & Chorrillos & Cementerio & $\begin{array}{l}\text { Formativo } \\
\text { Temprano } \\
\text { Formativo } \\
\text { Medio }\end{array}$ & $\begin{array}{l}800-520 \mathrm{AC} \\
390-190 \mathrm{AC}\end{array}$ & $\begin{array}{l}\text { Westfall y } \\
\text { González } 2010\end{array}$ \\
\hline Alto Loa & Talabre & Tal-26 & $\begin{array}{l}\text { Campamento } \\
\text { caravanero }\end{array}$ & $\begin{array}{l}\text { Formativo } \\
\text { Medio }\end{array}$ & $\begin{array}{l}830-190 \mathrm{AC} \\
770-210 \mathrm{AC}\end{array}$ & Pimentel 2013 \\
\hline Loa Medio & Calama & Topater & Cementerio & $\begin{array}{l}\text { Formativo } \\
\text { Medio } \\
\text { Formativo } \\
\text { Tardío }\end{array}$ & $410-170 \mathrm{AC}$ & $\begin{array}{l}\text { Fondecyt } \\
1110702\end{array}$ \\
\hline $\begin{array}{l}\text { Depresión } \\
\text { Intermedia }\end{array}$ & El Toco & A-299 & $\begin{array}{l}\text { Entierro } \\
\text { individual }\end{array}$ & $\begin{array}{l}\text { Formativo } \\
\text { Tardío }\end{array}$ & $\begin{array}{l}1890 \pm 40 \mathrm{AP} \\
1870 \pm 40 \mathrm{AP}\end{array}$ & $\begin{array}{l}\text { Cases et al. } \\
2008\end{array}$ \\
\hline $\begin{array}{l}\text { Depresión } \\
\text { Intermedia }\end{array}$ & $\begin{array}{l}\text { Pampa } \\
\text { Soledad }\end{array}$ & $\begin{array}{l}\text { Camachico } \\
27 \mathrm{~A}\end{array}$ & Ceremonial & $\begin{array}{l}\text { Formativo } \\
\text { Tardío }\end{array}$ & Por asociación & Pimentel 2013 \\
\hline $\begin{array}{l}\text { Depresión } \\
\text { Intermedia }\end{array}$ & Calate & $\begin{array}{l}\text { Línea de } \\
\text { Piedra CH-2 }\end{array}$ & Ceremonial & $\begin{array}{l}\text { Formativo } \\
\text { Tardío }\end{array}$ & Por asociación & Pimentel 2013 \\
\hline $\begin{array}{l}\text { Depresión } \\
\text { Intermedia }\end{array}$ & Calate & $\begin{array}{l}\text { Línea de } \\
\text { Piedra CH-3 } \\
\text { Norte }\end{array}$ & Ceremonial & $\begin{array}{l}\text { Formativo } \\
\text { Tardío }\end{array}$ & Por asociación & Pimentel 2013 \\
\hline
\end{tabular}


DC), se ha identificado una progresiva ocupación de los oasis, reflejada en asentamientos aldeanos de tamaño menor (Agüero y Uribe 2011), a veces asociadas a cementerios -como Chorrillos-, además del desarrollo de un modo de vida silvopastoril junto con la introducción de cultivos como el maíz (McRostie 2011; Vidal 2007). Finalmente (200 DC-500/900 DC), se define un periodo denominado Formativo Tardío en el que en los oasis los asentamientos se hacen bastante estables llegando a niveles aldeanos con estructuras de irrigación que evidencian mayor énfasis agrícolas. Se ha interpretado que los sistemas de integración social se visualizan en las diferencias identitarias expresadas especialmente en la cultura material a través de un utillaje característico y expresiones territoriales como el uso de cementerios (Barón 1986; Thomas 1995). En el Loa superior este periodo se extendería hasta el $900 \mathrm{DC}$, al no observarse el ingreso de la cultura Tiwanaku (Sinclaire 2004).

Las actividades artesanales comienzan a constituirse en un eje central de organización del tiempo, en correspondencia con la importancia que adquieren dentro de la sociedad pues la surten no solo de artefactos domésticos que dan cuerpo a los nuevos modos de producción y organización social, sino sobre todo de artefactos con alto valor simbólico utilizados en rituales. Objetos que además son intercambiados a veces a través de largas distancias, sirviendo en la negociación política y social con otros grupos de otras localidades y regiones. Esto como parte de un contexto general de diversificación en el uso de algunas materias primas y la aparición de tecnologías antes inexistentes que se incorporan paulatinamente, tales como la arquitectura en piedra y barro, la aparición de metales, cerámica, y textilería (Agüero y Uribe 2011; Agüero et al. 2006; Núñez et al. 2006b).

Respecto a la alfarería, esta actividad se ha considerado como parte de un desarrollo local de conocimientos compartidos con otras áreas de los Andes circumpuneños, lo que sugeriría la existencia de intensas actividades de contacto y comunicación entre los grupos implicados (Uribe 2006), observándose patrones más domésticos en el Loa (Pollard 1971; Sinclaire et al. 1997) y más ceremoniales en Quillagua (Agüero et al. 2006; Uribe y Ayala 2004). Esta idea no parece ser aplicable a todos los objetos, por ejemplo, en el caso de los artefactos de metal no se han registrado hasta el momento evidencias ni de herramientas ni de contextos de trabajo que atestigüen sobre áreas de producción. Solo hay registro de piezas metálicas en contextos rituales en forma de escasas láminas de metal nativo martillado, a veces formando figuras antropomorfas (Núñez et al. 2005). El caso de los textiles propone un necesario análisis más amplio, dado que su evolución va de la mano con la del ganado camélido. Hace varias décadas se ha establecido que estos animales fueron necesarios para el transporte de carga, pero también cada vez queda más claro que su manejo estuvo orientado a la producción de lana. Además de ello, se ha observado que el uso de los camélidos como materia prima es más amplio, siendo sus huesos utilizados como soporte de herramientas, entre ellas las de tejido (Santander et al. 2016). Los objetos registrados en torno a la textilería no son muchos, sin embargo, permiten pensar sobre el tiempo invertido en hilado, teñido y tejido.

En cuanto a los objetos perforados se registran bastante ubicuos, aunque con variaciones notables en su número además de una diversificación en las materias primas utilizadas respecto al periodo anterior (Soto 2006). La distribución de los objetos perforados dentro de los sitios arqueológicos y a nivel regional nos ha llevado a concluir que principalmente son depositados intencionalmente en contextos de alto valor simbólico, como entierros y sitios ceremoniales (Soto 2009, 2015). Aunque en algunos sitios ha sido posible documentar la cadena operativa de fabricación de estos artefactos, hasta el momento se ha considerado el carácter significativo de esta actividad si consideramos su relación contextual con el resto del depósito estratigráfico y disposición general en lugares de entierro como ha sido descrito para Quillagua (Agüero et al. 2001; Carrasco 2002), o ceremoniales como en Tulán 54 y Tulán 85 (Soto 2006).

La producción de objetos perforados es un ejemplo de este proceso de especialización generalizado de las sociedades de la Circumpuna y los Andes Centro-sur, en un momento en que la producción de cultura material se amplía y diversifica, en especial su uso en un sistema simbólico ritual. Por otra parte, son un objeto circulante ejemplar, en tanto materia prima con alto valor simbólico y en cuanto producto con valor agregado (Soto 2015). Considerando el momento al que nos enfrentamos, donde la inversión de tiempo en actividades relacionadas con las artesanías transforma los modos de vida, aportando junto con otras actividades (p.ej., silvopastoralismo) a la construcción y legitimación de una nueva organización social, política y económica, parece interesante tomar los objetos perforados como punto de partida para aportar a la teorización sobre otro aspecto destacado en las definiciones del periodo como es la circulación y el intercambio. Estos son objetos dúctiles que fueron portados tanto individualmente o como parte de otros objetos, y que pudieron por tanto circular como conjunto o como pieza única ayudándonos a reflexionar sobre el amplio arco entre dones y mercancía, como dos polos relacionables con lo que queda excluido de la circulación mercantil, lo que se obsequia y lo que se transa e intercambia.

\section{Los sitios arqueológicos y los conjuntos de objetos perforados}

El templete de Tulán 54 (cal. 910-760 AC) está ubicado en las cercanías de la localidad de Peine al sur de salar de Atacama. Este se caracteriza por su construcción 
monumental de piedra, en cuya estratigrafía y depósitos de basura se registran gran cantidad de elementos que han permitido a los investigadores plantear su función como lugar de peregrinaje. Este sitio se vincula con desarrollos similares de las áreas vecinas del Titikaka y el Altiplano meridional boliviano y NOA. Se observa que en el sitio fueron realizados festines, ofrendas y producción ritual de artefactos (Núñez et al. 2006a; 2006b; 2017). Se analizaron 1728 objetos perforados de distintas materias primas, provenientes de quince de los 24 entierros de neonatos excavados en el interior del templete. Se identificaron piezas discoidales de concha $(n=712)$ cuyos rangos de tamaño van entre los $5 \mathrm{~mm}$ y los $8 \mathrm{~mm}$. Estas son de sección plana, pero de un grosor mayor que las fabricadas en conchas delgadas por lo que se considera fueron efectuadas en valvas del océano Pacífico, siguiendo patrones comunes a sitios del periodo Arcaico, conclusión ampliamente expuesta en trabajos anteriores (Soto 2006, 2009). Además, se registraron cuentas de mineral de cobre $(n=491)$, piedras azules $(n=108)$ y caliza $(n=416)$ de color blanquecino, características porosas y aspecto desagregado, podría tratarse también de 'ganga' o costra de mineral de cobre. Más de la mitad de los entierros presentan cuentas de mineral de cobre, aunque solo en el caso del cuerpo 7 en gran cantidad (276 cuentas de mineral de cobre) (Figura 5).

Otro sitio utilizado en este estudio es el cementerio de Chorrillos (cal. 850-190 AC), el que se emplaza en las orillas del Río Loa. Debido a su cercanía al río, presenta muy mala conservación y un depósito calcáreo el cuál fue excavado en fosas para el entierro múltiple de individuos. En 259 fosas se contabilizaron un total de 353 individuos provenientes de entierros primarios y secundarios con escasas ofrendas. De los cuerpos localizados solo 20 presentaron objetos perforados, principalmente collares de concha de varios cientos de objetos perforados. Este cementerio se vincula con antecedentes publicados sobre los desarrollos vecinos de Chiu Chiu y el Salar de Atacama a través de elementos exóticos como productos de la costa y láminas de oro asociadas a neonatos, aunque a diferencia de dichas áreas vecinas en Chorrillos las evidencias se inclinan por un carácter más agrario que pastoril, debido a la presencia por ejemplo de palas líticas (González y Westfall 2010). En este sitio fueron documentados 5230 objetos perforados asociados a 36 individuos (Figura 6). Los tipos identificados corresponden a conchas $(n=4838)$, siendo el tipo más abundante el discoidal mínimo con 4725 objetos perforados. Destaca la asociación de estas piezas a individuos femeninos y de sexo no identificado. También destacan piezas efectuadas en nódulo natural $(\mathrm{n}=107)$ asociadas a un individuo con deformación craneana circular de entre seis y 12 años de edad. Al igual que en los otros sitios la otra materia prima numerosa es el mineral de cobre $(n=389)$, en la que además se identificaron 20 fragmentos pulidos, 13 preformas con el borde claramente formatizado y tres con evidencias de perforación, que constituyen evidencia del proceso artesanal in situ. Destacan tres objetos perforados discoidales de piedra azul y una figura antropomorfa de piedra (Figura 7).
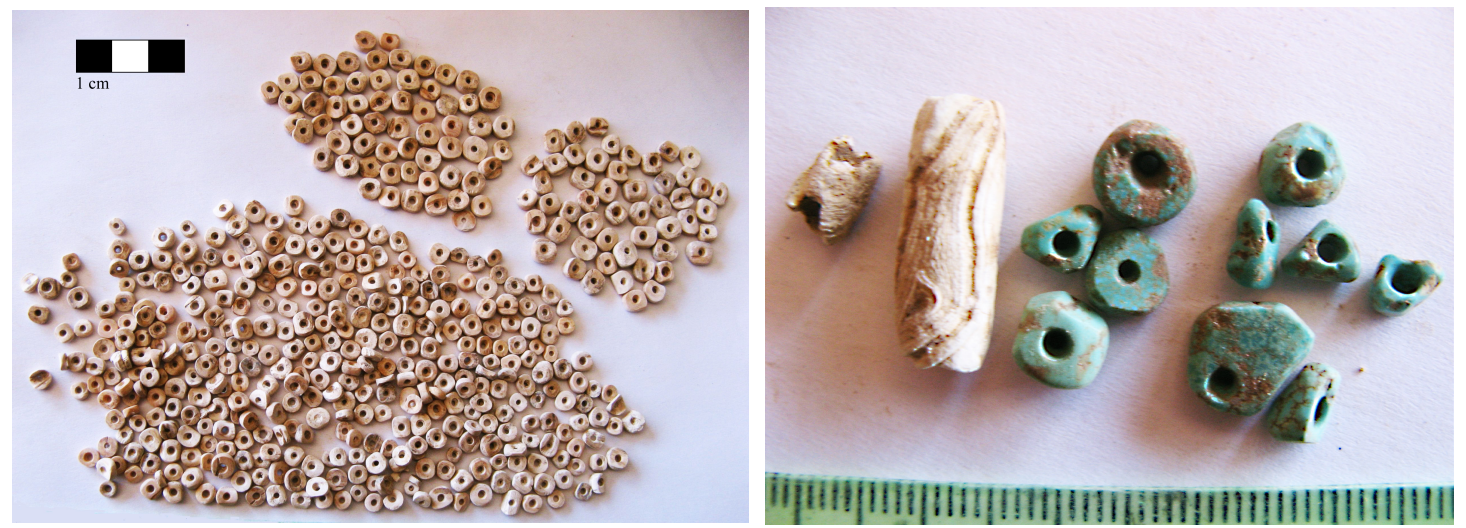

Figura 5. Sitio Tulán 54, objetos de concha (izq.) y mineral de cobre (derecha).

Tulan 54 site, shell objects (left) and copper ore (right). 


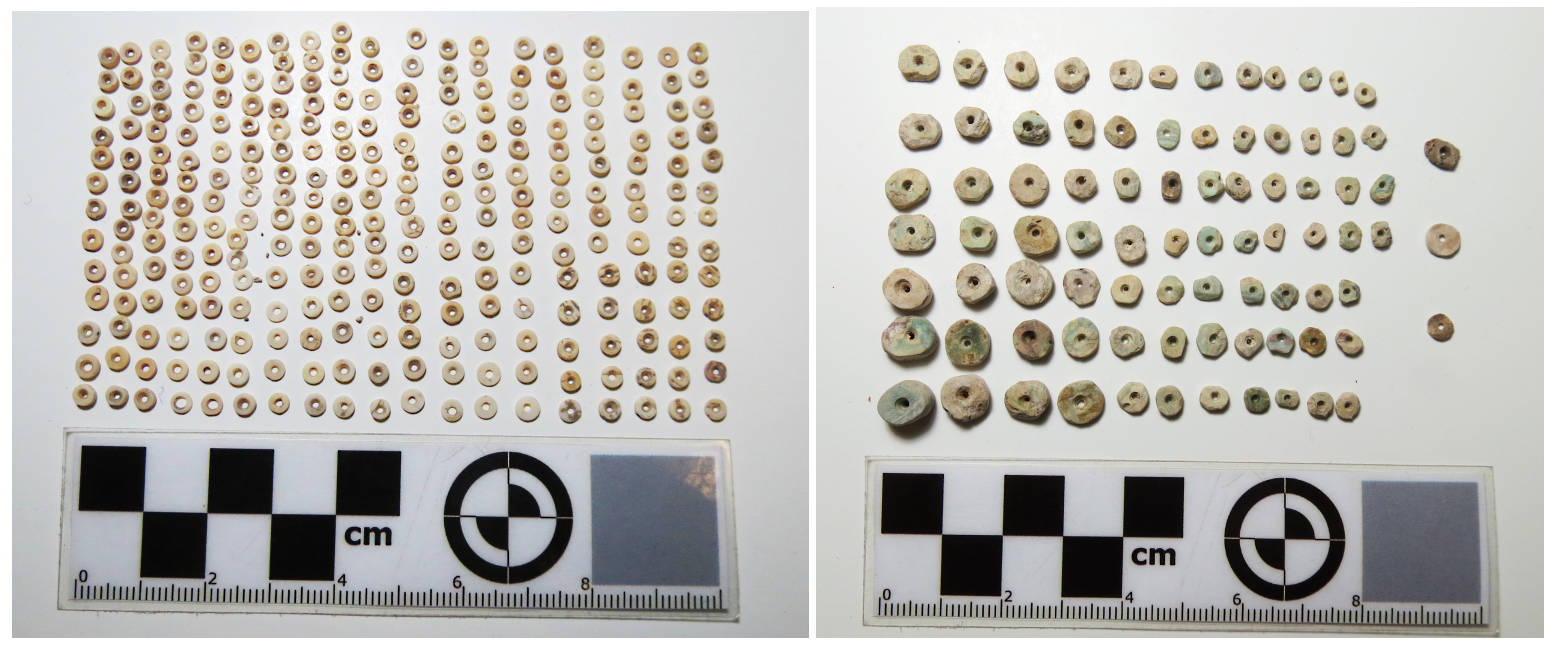

Figura 6. Sitio Chorrillos, objetos de concha (izq.) y mineral de cobre (derecha).

Chorrillos site, shell objects (left) and copper ore (right).

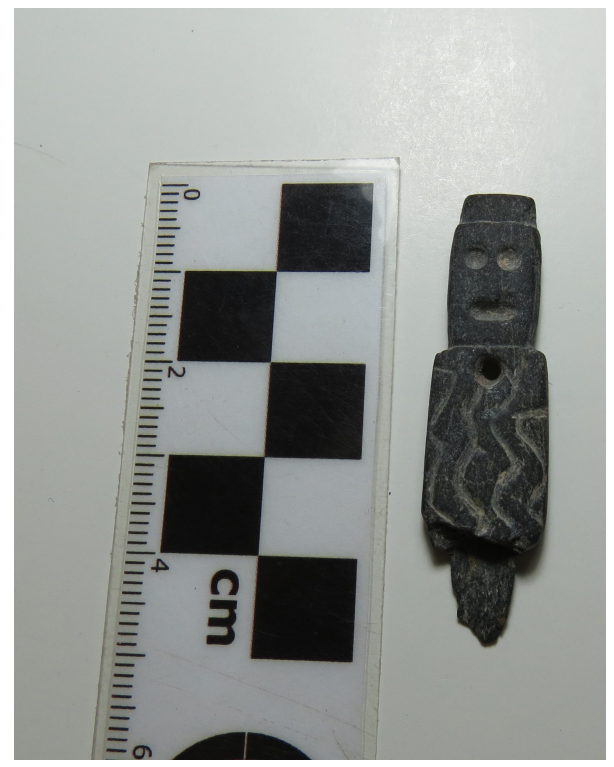

Figura 7. Sitio Chorrillos, pendiente lítico antropomorfo, proveniente de Unidad F 17 Fosa 3 Individuo 1-2.

Chorrillos site, anthropomorphic lithic pendant, from Unit F 17 Pit 3 Individual 1-2.

El tercer sitio analizado fue el cementerio de Topater 1 (cal. 410-170 AC) emplazado al Este de la ciudad de Calama en el cerro homónimo. Es un sitio que presenta una excelente conservación por lo que las piezas en mejor estado y calidad provienen de allí. Sin embargo, solo contamos con el breve artículo de Thomas et al. (1995) quienes interpretan la colección identificando dos componentes en los entierros, uno compuesto por fardos y el otro correspondiente a huesos humanos articulados y desarticulados. Los materiales asociados a este sitio son de una complejidad técnica particular, en especial textiles y cestos, entre los que se contabilizan múltiples funcionalidades. Destacan los penachos (tocados cefálicos) y atados de plumas, las conchas del Pacífico algunas envueltas en tejidos que protegen pigmentos, miniaturas de cerámica, sacos de cuero con semillas en su interior, objetos de hueso, objetos perforados, etc. Análisis efectuados a los textiles y la cerámica del sitio lo vinculan con tradiciones del Loa Medio (oasis de Chiu Chiu), pero 
también con áreas más alejadas como Quillagua y la desembocadura del Loa (Agüero et al. 2006). Para este sitio se analizaron 1552 objetos perforados, provenientes de 18 unidades de excavación $(n=803)$ y otros sin contexto identificado $(n=749)$. Destacan en el contexto analizado los conjuntos de piezas que agrupados conforman una pieza mayor, tales como dos collares sin contexto de semillas y de mineral de cobre, una huincha o pulsera con cuentas de concha y una figurilla de arcilla con objetos perforados de concha a modo de tocado. La mayor cantidad corresponde a objetos de Concha $(n=952)$ identificadas en tres casos, aisladas, tejidas entre la trama de una huincha o pulsera y asociadas al Cuerpo 2 (Figura 8).

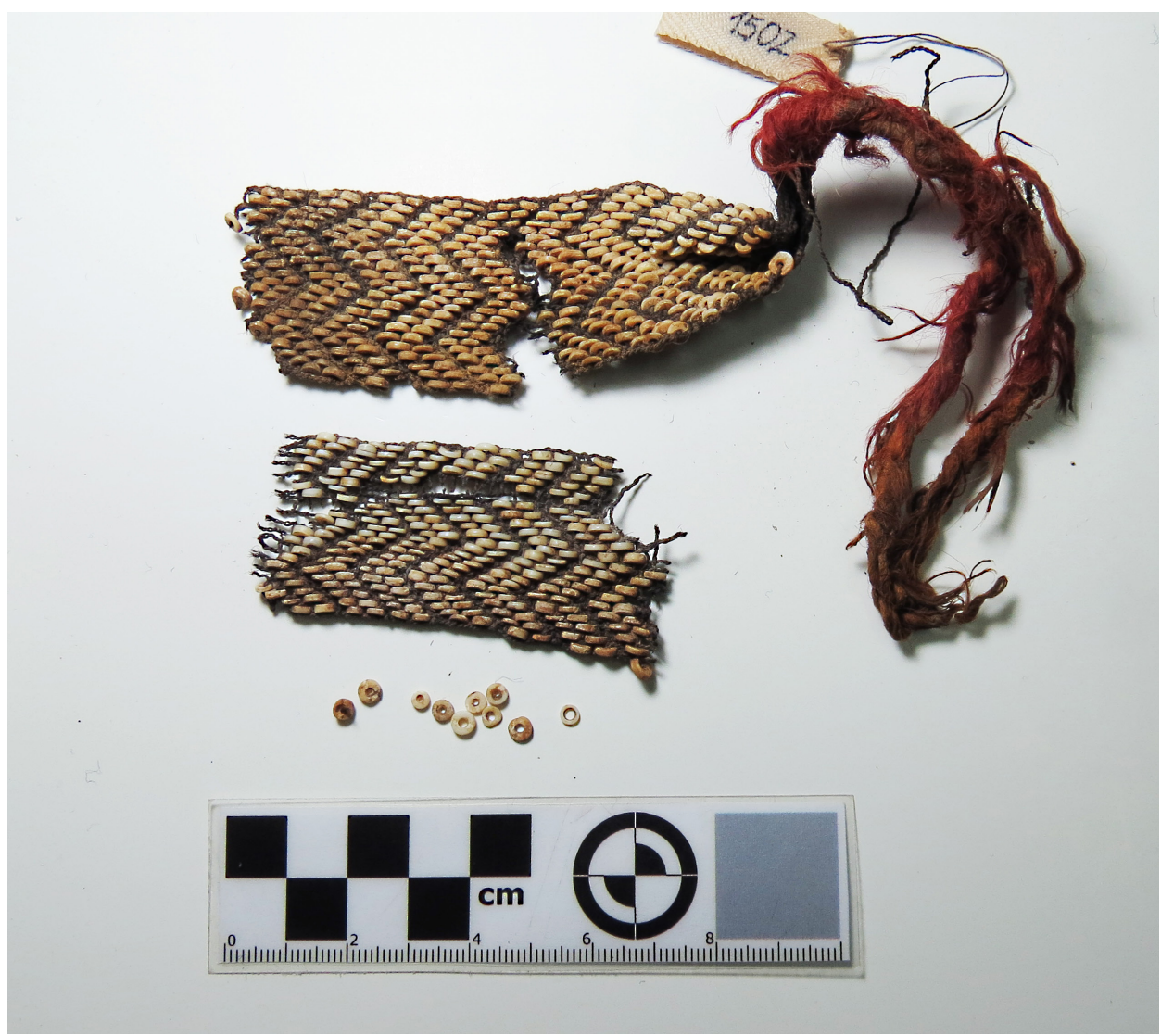

Figura 8. Topater 1, huincha tejida con objetos perforados y configuración en zig-zag en lana de camélido con terminación teñida de rojo.

Topater 1, weaved band with perforated objects and zigzag arrangement in camelid wool with red-dyed tip.

Sin contexto se analizaron 231 cuentas que estaban hiladas como collar post excavación. Además, algunas piezas del tipo discoidales grandes con muesca tejidas en tocado de pelo humano de figurilla antropomorfa femenina de arcilla $(n=57)$ (Figura 9). Se registra también una pieza tubular de óseo $(n=2)$, metal $(n=3)$, lítico $(n=6)$, semillas ( $n=431$, solo 40 asociadas a un cuerpo el resto descontextualizadas), mineral de cobre $(n=160)$, siete de ellas tubulares grandes corresponden una sarta de cuentas tubulares conformado de diferentes tamaños e hilado en $\langle Z\rangle$ doble de lana de camélido (Figura 10) y ocho asociadas a un entierro que están unidas por hilado de pelo de camélido.
Respecto a los contextos asociados a caminos de los sectores de Pampa El Toco, salar de Talabre y Pampa Soledad (2013). Los excepcionales caminos del Desierto de Atacama, nos entregan información concreta respecto a la dirección y objetivo de los movimientos de pequeñas y larga distancias. El registro de estos contextos ha permitido detectar la presencia de dos modalidades en el tráfico desde el periodo Formativo: una costera y otra caravanera (Pimentel et al. 2011). Junto con ello, el hallazgo de contextos fúnebres en medio de la pampa en los sectores de Cerro El Mono, Pampa El Toco y Calate han dado pruebas de que 
los agentes del viaje fueron grupos compuestos por individuos de diferentes sexos y edades (Torres-Rouff et al. 2012). En el sector de Talabre, en el campamento de paso Tal-26 (cal. 830-190 AC) fueron identificados restos de mineral de cobre, cuentas y una valva de Oliva peruviana, esta última comúnmente identificada como colgante o adorno. Por otra parte, en el sector de Pampa Soledad fueron identificados objetos perforados de placas calcáreas (Figura 11) y mineral de cobre en los sitios ceremoniales de Camachico 27A, y las líneas de piedra CH-2 y CH-3 Norte, estos tres últimos han sido asociados a través de indicadores materiales al Formativo Tardío. Cada uno de estos contextos tiene un vínculo con una subregión particular, siendo interesante su vinculación directa con el paisaje y prácticas locales y panregionales.

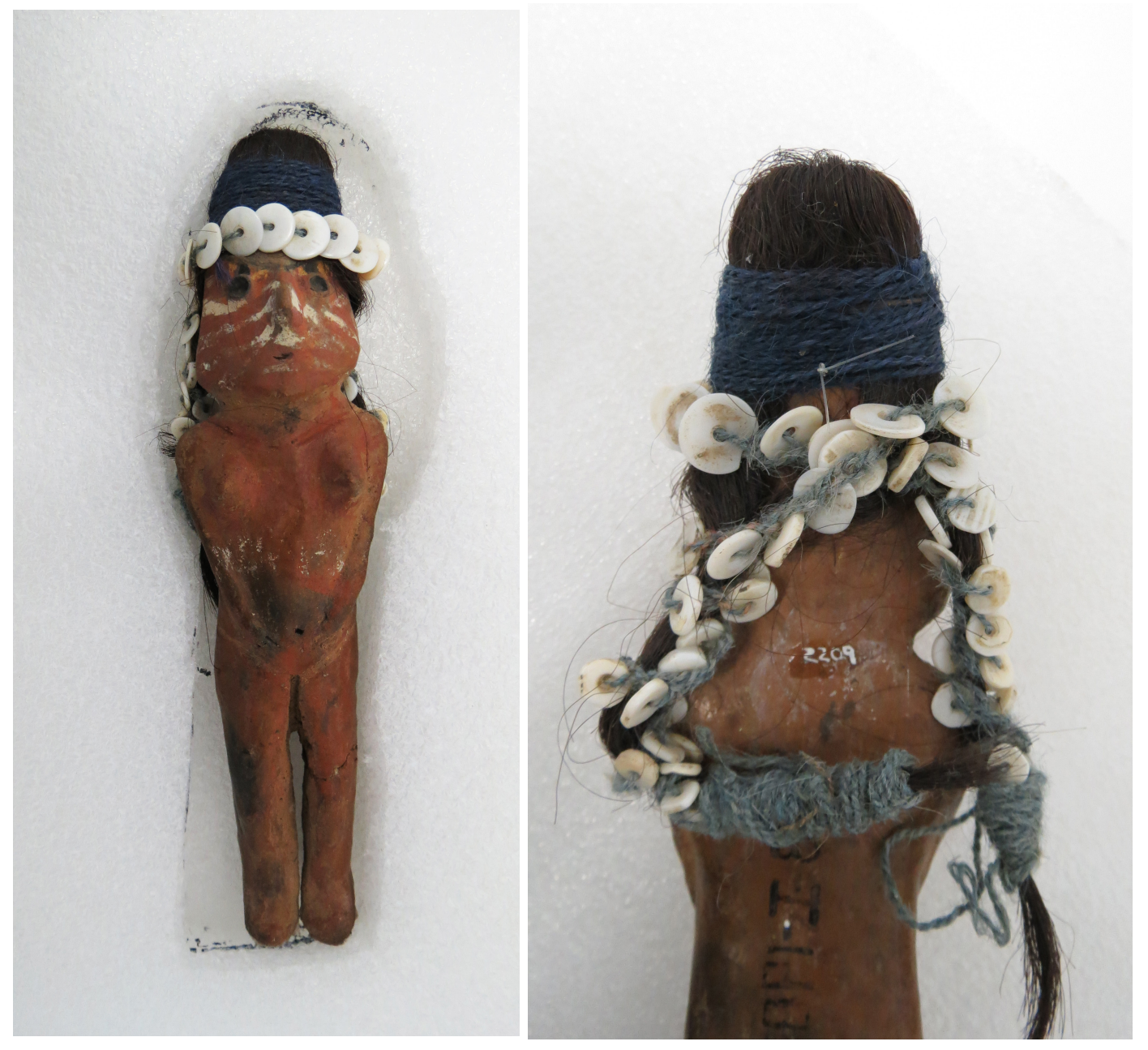

Figura 9. Topater 1, una figurilla de arcilla con 57 piezas a modo de tocado y tejidas en pelo humano.

Topater 1, clay figure with 57 pieces as headdress and weaved in the human hair. 


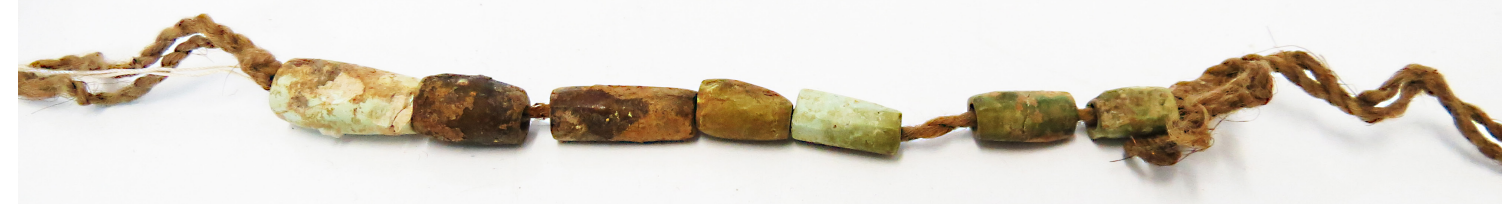

Figura 10. Topater 1, sarta de siete piezas tubulares de mineral de cobre, hiladas en lana de camélido.

Topater 1, string of seven tubular copper ore pieces, spun in camelid wool.
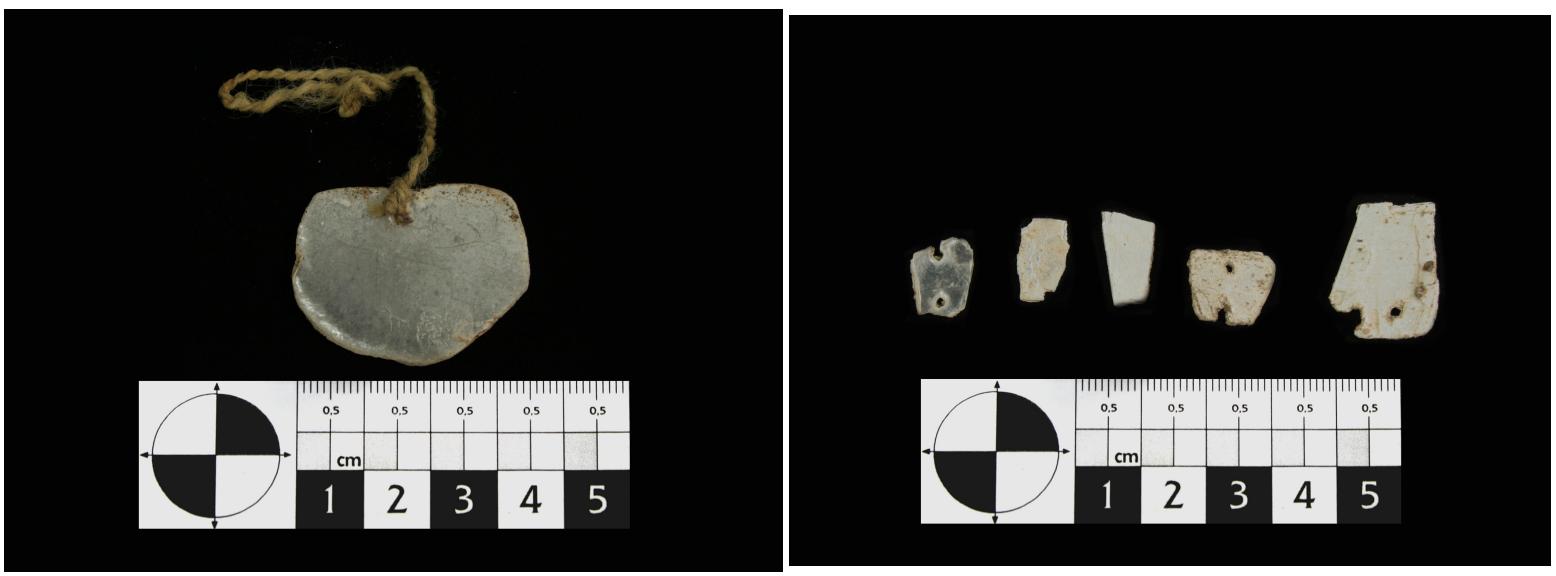

Figura 11. Izquierda, pendiente de cristal de yeso con amarra; derecha placas de cristal de yeso con perforaciones, similares a las descritas para Quillagua por Carrasco (2002). Proveniente de CH-2, Calate.

Left, gypsum-crystal earring with tie; right, gypsum-crystal plates with perforations, similar to those described for Quillagua by Carrasco (2002). From $\mathrm{CH}-2$, Calate.

\section{"Enmarañamiento" o Entanglement: Los Objetos Perforados del Desierto de Atacama}

A partir del análisis bibliográfico de las investigaciones publicadas con cierta información sobre las características del conjunto de objetos perforados, y una propuesta tipológica basada en un conjunto de alrededor de 8000 piezas, se ha generado una síntesis respecto a las características, contextos y distribución de los objetos perforados del periodo Formativo atacameño. Antes de comenzar la discusión me parece importante señalar que una característica principal de los objetos perforados analizados en este estudio es su tamaño y durabilidad. Estos son objetos que pueden ser transportados ensartados y en grandes volúmenes sin que se dañen y pierdan. Pueden ser fácilmente contabilizados (y utilizados para contar). El uso de objetos idénticos como especies de monedas se ha observado en otras regiones (Gassón 2005).

La mayor parte de piezas observadas proviene del cementerio de Chorrillos (60\%) de las que cerca de un $90 \%$ corresponden a piezas de concha que componen collares (Figura 6). La misma situación se observa en el sitio Tulán 54, en donde además de observarse la presencia de collares de concha junto a entierros de neonatos (Soto 2009) (Figura 5). Se observa que 
fuera de estos contextos es donde predominan las cuentas de mineral de cobre en proceso de fabricación y terminadas, pero descontextualizadas, es decir, no formando parte de otros objetos. Por otra parte, destacan los objetos perforados del sitio de Topater, en donde además de registrarse tres conjuntos o sartas de mineral de cobre hiladas en pelo de camélido (ejemplificados en Figura 10), se rescataron dos piezas de características excepcionales la figurilla de arcilla con piezas de concha a modo de tocado y tejidas en pelo humano (Figura 9), $\mathrm{y}$ una especie de huincha con objetos perforados entre tejidos (Figura 8). Aunque aún no se han hecho análisis de componentes químicos, según análisis comparativos micro y macroscópicos estas cuentas parecen corresponder a Sthrophocheilus oblongus.

En los diferentes sitios se observa la presencia constante de objetos perforados de mineral de cobre, a veces conformando sartas o collares en especial en Tulán 54 y Topater, aun cuando los collares de concha tienen más piezas. No deja de ser notorio entonces el predominio de las piezas de concha por sobre las otras materias primas considerando que, en el área solo se ha verificado con claridad la producción de objetos perforados en la materia prima local o mineral de cobre (Rees 1999; Soto 2006) y es más interesante aún si consideramos que en los contextos donde abundan estas materias primas exóticas son fúnebres y rituales. Es notable también, que en los contextos de rutas las piezas de concha están prácticamente ausentes, habiendo un predominio del uso de mineral de cobre y materias primas locales como las placas calcáreas en las áreas cercanas a Quillagua vistas en este análisis y en los de otros autores (Carrasco 2002).

Parece interesante entonces retomar esta diferencia numérica de las piezas de concha por sobre las de mineral de cobre en los diversos sitios y contextos analizados. A la luz de las propuestas teóricas revisadas anteriormente respecto a la circulación de objetos, es posible que algunos de ellos transiten en su biografía por múltiples y "enmarañados" procesos de objetivación y subjetivación (Kopytoff 1991), debido a cualidades particulares definidas contextual e históricamente. En este caso podríamos plantear que de manera más elocuente los objetos perforados que son parte de ciertos artefactos tienen la característica de ser subjetivados hasta el punto de ser depositados en un contexto final de tipo ritual, como ceremonias fúnebres y de ofrenda, funcionando en una esfera simbólica y ritual. Este es el caso de los artefactos que poseen objetos perforados de concha e incluso las conchas mismas (Soto 2009), los que podrían ser incluso parte de 'desviaciones controladas' en donde estos objetos con flujo restringido estarían al servicio de la reproducción de los sistemas ideológicos y políticos (Appadurai 1991:42). La subjetivación se observaría con mayor claridad en los objetos que configuran piezas completas -casi todas las observadas en este estudio son únicas- y que por tanto debieron circular como lo que la antropología denomina "dones", mereciendo por ello su entierro junto a los difuntos locales. Pero también algunas de estas piezas pudieron ser adquiridas en un sistema de intercambio objetivado, siendo integradas a estos objetos únicos que fueron creados para ser subjetivados asegurando su salida rápidamente del contexto sistémico.

Por otra parte, y como una segunda esfera de significado consideramos el intercambio extensivo, en que podríamos identificar procesos de objetivación de las piezas fabricadas en la materia prima local del Desierto de Atacama: el mineral de cobre. Se han documentado contextos formativos de producción de objetos perforados en esta materia prima, en Tulán 54 (Soto 2006), Tulán 85 y en el alto Loa (Rees 1999), además de al menos un asentamiento minero en el sector de El Abra, el sitio Cerro Turquesa datado a partir del 200 DC -aunque su auge de explotación se verificaría entre los 800-1200 DC en el periodo Intermedio Tardío(Salazar et al. 2010). Podemos proponer entonces que la materia prima local es extraída, procesada y transformada con la intención de acumular excedentes que son utilizados en la esfera del intercambio, con la finalidad de obtener otros objetos de alta valoración social. La especialización simbólica y tecnológica en torno a su extracción y procesamiento habría generado nuevos sistemas de asentamiento y organización social según las necesidades de inversión de tiempo y conocimientos, sin dejar de ser compatibles con la actividad pastoril. En especial, estos funcionarían en el ámbito de la objetivación cuando se encuentran descontextualizados de otros artefactos locales seguramente en espacios que hoy se han denominado como internodales. En el caso exclusivo de las valvas del Pacífico, la materia prima podría haber circulado desde los enclaves costeros hacia el interior, siendo valorada por las poblaciones costeras como un artefacto intercambiable/objetivado, y es seguramente por esta característica que Llagostera (1996) y Nielsen (2013) pueden incluirla entre los bienes de circulación no restringida. Para el caso de Strophocheilus también se identifica un tránsito, con significaciones diferentes, que es rastreable en diferentes áreas de la vertiente oriental de la cordillera de los Andes (p.ej., Pastor et al. 2017), siendo objeto de un intercambio objetivado o más mercantilizado desde los lugares en donde se localiza su hábitat y es de más fácil obtención. Seguramente los valores se transformaron cuando llegaron a manos de consumidores para los que no fue sencillo obtener la materia prima, sublimando sus significados altamente "enmarañados" y volviéndose objetos menos objetivados, más subjetivados.

Es de relevancia apuntar que las materias primas en discusión que dan soporte a los objetos perforados 
tienen un valor simbólico de referencia en los Andes, siendo relacionadas como frutos (mamas o illas) de sus lugares de origen en el mar (Davison 1981; Murra 2002) o en la tierra (Bouysse-Cassagne 2004; SalazarSoler 1992). El mineral de cobre es una materia prima producida localmente, con su propia complejidad técnica de extracción, teniendo registro desde el periodo Arcaico Tardío de su utilización y modificación, además de la documentación de fuentes o minas en la región como Cerro Turquesa. La concha por su parte proviene de lugares distantes cientos de kilómetros, como la costa Pacífica y al otro lado de la cordillera de los Andes, en el NOA. En este caso se observan vínculos simbólicos relacionables con los estados acuáticos, pero también con la predicción del clima en las localidades de la costa, de artefactos que están circulando desde el periodo anterior (Soto y Power 2013).

Considerando las anteriores posibilidades, y tomando en cuenta el valor asociado con las propiedades físicas de las materias primas, sin duda, los objetos perforados constituyen bienes de significado complejo en términos semióticos y económicos, dadas sus múltiples relaciones con el espacio, las personas, sus dificultades de obtención y los procesos que les han transformado. Debido a ello el calificativo de "enmarañado" o entanglement (Thomas 1991) puede definir ese potencial contenido en la pieza individual y en la configuración más compleja -como la figura de arcilla con tocado de cuentas- de objetos que no son transados bajo ninguna forma cercana a la objetivación o mercantilización, sino que entregados como dones. Es decir, que cuando las piezas se vuelven escasas operan con mayor claridad los procesos de subjetivación, mientras que cuando los grupos pueden producir excedentes los objetos que además tienen un valor en tanto materia prima pueden transitar por una gradiente de opciones entre la objetivación y la subjetivación cuya forma es definida desde las relaciones sociales que están en acción.

\section{Conclusiones}

Sin duda, si integramos la idea de que los objetos perforados son mucho más que objetos misceláneos y cuentas de collar nos pueden interrogar y sugerir espacios hasta ahora poco explorados de la vida social andina, a partir de sus infinitas posibilidades de utilización. Vistos en esta ocasión como objetos de intercambio cuyos usos observados son variables según el origen de la materia prima nos abre nuevas posibilidades de interpretación respecto a los tipos de relaciones sociales entre grupos cercanos y distantes que configuraron el espacio social, simbólico y el territorio habitado por las poblaciones del Desierto de Atacama, de la Subárea Circumpuneña e inclusive de los Andes Centro-sur.

Como se sugirió en un estudio anterior para las valvas de molusco (Soto 2009), observamos al menos dos esferas de circulación de nuestros materiales de estudio, una ritual o donde los objetos perforados de materias primas exógenas son subjetivados hacia dentro del grupo, pudiendo ser intercambiadas como dones entre personas cercanas; y otra esfera relacionada con relaciones de intercambio con consumidores distantes, en donde el grupo objetiva la materia prima local al hacerla circular para obtener bienes y materias primas exóticas. El considerar de manera flexible esta propuesta de funcionamiento de los objetos en distintas esferas, nos permite comenzar a dar un paso adelante respecto a la clásica e idealizada visión de la reciprocidad y la obligación como fundantes de las relaciones andinas. Por el contrario, nos permite afirmar la tesis del rol central del intercambio en los procesos económicos que sustentan y legitiman una organización social del tiempo y del espacio surandino incluso en el periodo Formativo.

En el caso de los objetos perforados, podríamos comentar que a través de sus propiedades permiten la creación de espacios sociales, ratificando vínculos y alianzas simbólicas a través de su materialidad. Con esta cualidad se convierten en agentes activos en el proceso de estructurar, reproducir y/o subvertir las relaciones sociales, tanto si su circulación se debe a intenciones de corto o largo aliento, en el tiempo y en el espacio (Lazzari 1999:20). Su potencial como objetos valiosos tiene bastante asidero respecto a sus usos (como adorno, como ajuar, como ofrenda) y materias primas (del mar y la tierra), los que pueden tener mayor peso dependiendo desde donde se observe la circulación. Situándonos en el Desierto de Atacama, observamos que los artefactos que incorporan objetos perforados de concha son singularizados como marcadores identitarios (Chorrillos) y al extremo de su salida total del circuito en su depósito como ofrenda u ajuar del difunto. Mientras que los objetos perforados de mineral de cobre se objetivan cuando se encuentran a 'granel' dispuestos para su traslado a largas distancias, sin desmarcarse de su utilización como amuletos o marcadores identitarios. Un dato más que puede ser añadido es que cuentas de collar han sido utilizadas en otras partes del mundo como especies de moneda, como es el caso estudiado por Gassón (2000) a través de documentos etnohistóricos en la Cuenca del Orinoco. De manera semejante, en otros espacios de los Andes se ha observado la presencia de objetos de uso mercantil (coca, ají, conchas) asociadas a instrumentos de medición por Espinoza Soriano (1987) entre los reinos costeros Chimú y Chincha durante el Periodo Tardío.

Finalmente, es interesante por lo menos discutir la idea de esferas de intercambio divididas en restringidas y no restringidas (Nielsen 2013), pues como hemos revisado en el caso de los objetos perforados estos pueden transitar de un espacio a otro dependiendo del contexto que enuncia la acción de intercambiar, y dependiendo de los usos y significados que cada localidad, región o área le dé al objeto. Esto convierte a los objetos perforados 
en artefactos con un alto potencial para circular en un contexto de tráfico especializado o integrado y ser intercambiados como dones (subjetivación) o como mercancías (objetivación) -o en una situación en la que las personas que intercambian no establecen una relación social permanente. Este funcionamiento en esferas económicas, simbólicas y sociales múltiples nos permite confirmar que son objetos con una textura compleja y altamente "enmarañados" con sus propias asociaciones simbólicas y en relación con otros objetos, sujetos y paisajes en los que son depositados. Es consecuencia, su significado es altamente relacional.

Agradecimientos: Este trabajo fue financiado por CONICYT PFCHA/DOCTORADO BECAS
CHILE/2016 - 21160739. Este texto es resultado de mi investigación de magíster, guiada por Paulina Faba, y del seminario de investigación doctoral, guiado por Alejandra Vega. A ambas profesoras brillantes les agradezco la guía y lucidez. Así mismo agradezco a la Corporación Cultural el Loa, y los investigadores principales de los proyectos FONDECYT 1070040, Lautaro Núñez, FONDECYT 1110702, Francisco Gallardo y a en diferentes proyectos de Gonzalo Pimentel, por permitirme analizar el material que fue el corpus principal de esta investigación. Quiero agradecer a Marisa Lazzari por su estimulante, desinteresados comentarios y acuciosa revisión. Finalmente, a los evaluadores anónimos que contribuyeron a mejorar este artículo.

\section{Referencias Citadas}

Agüero, C. 2005. Aproximación al asentamiento humano temprano en los oasis de San Pedro de Atacama. Estudios Atacameños 30:29-60.

Agüero, C., P. Ayala, M. Uribe, C. Carrasco y B. Cases 2006. El Período Formativo desde Quillagua, Loa Inferior (norte de Chile). En Esferas de Interacción Prehistóricas y Fronteras Nacionales Modernas: Los Andes Sur Centrales, editado por H. Lechtman, pp. 73-120. Instituto de Estudios Peruanos, Lima.

Agüero, C. y M. Uribe 2011. Las sociedades Formativas de San Pedro de Atacama: asentamiento, cronología y proceso. Estudios Atacameños 42:53-78.

Agüero, C., M. Uribe, P. Ayala, B. Cases y C. Carrasco 2001. Ceremonialismo del Período Formativo en Quillagua, Norte Grande de Chile. Boletín de la Sociedad Chilena de Arqueología 32:24-34.

Appadurai, A. 1991. Introducción. Las mercancías y la política del valor. En La Vida Social de las Cosas: Perspectiva Cultural de las Mercancías, editado por A. Appadurai, pp. 1788. Consejo Nacional para la Cultura y las Artes, México DF.

Bandy, M.S. 2004. Trade and social power in the southern Titicaca Basin Formative. Archeological Papers of the American Anthropological Association 14 (1):91-111.

Barón, A.M. 1986. Tulor: posibilidades y limitaciones de un ecosistema. Chungara Revista de Antropología Chilena 16/17:149-158.

Benavente, M.A. 1981. Chiu-Chiu 200: Un Campamento de Pastores. Tesis para optar al grado de Licenciada en Prehistoria. Departamento de Historia, Facultad de Filosofía y Educación. Universidad de Chile, Santiago.

Blanton, R.E., G.M. Feinman, S.A. Kowalewski y P.N. Peregrine 1996. A dual-processual theory for the evolution of Mesoamerican civilization. Current Anthropology 37 (1):1-14.

Bourdieu, P. 1997 [1977]. Outline of a Theory of Practice. Cambridge University Press, Cambridge.

Bouysse-Cassagne, T. 2005. Las minas del centro-sur andino, los cultos prehispánicos y los cultos cristianos. Bulletin de l'Institut Français d'Etudes Andines 34 (3):443-462.
Browman, D.L. 1980. Tiwanaku expansion and altiplano economic patterns. Estudios Arqueológicos 5:107-120.

Carrasco, C. 2002. Las industrias líticas de Quillagua durante el Período Formativo, en el contexto del Norte Grande. Estudios Atacameños 22:33-57.

Cartajena, I. 1994. Determinación de restos óseos de camélidos en dos yacimientos del Loa Medio (II Región). Estudios Atacameños 11:21-49.

Castro, V., J. Berenguer, F. Gallardo, A. Llagostera y D. Salazar 2016. Vertiente Occidental Circumpuneña. Desde las sociedades posarcaicas hasta las preincas (ca. 1500 años a.C. a 1470 años d.C.). En Prehistoria en Chile: desde sus Primeros Habitantes hasta los Incas, editado por F. Falabella, M. Uribe, L. Sanhueza, C. Aldunate y J. Hidalgo, pp. 239-284. Editorial Universitaria, Santiago.

Davison, J. 1981. El Spondylus en la cosmología Chimú. Revista del Museo Nacional de Lima XLV:75-87.

Espinoza Soriano, W. 1987. Artesanos, Transacciones, Monedas y Formas de Pago en el Mundo Andino: Siglos XV y XVI. Banco Central de Reserva del Perú, Lima.

Gallardo, F. 2013. Sobre el comercio y mercado tradicional entre los Lupaca del siglo XVI: un enfoque económico Sustantivo. Chungara Revista de Antropología Chilena 45 (4):599-612.

Gassón, R. 2000. Quiripas and mostacillas: The evolution of shell beads as a medium of exchange in northern South America. Ethnohistory 47 (3/4):581-609.

González, C. y C. Westfall 2010. Cementerio Regimiento Chorrillos de Calama: testimonios funerarios formativos en el Loa Medio, Región de Antofagasta. Actas XVII Congreso Nacional de Arqueología, editado por Sociedad Chilena de Arqueología, pp. 95-105). Universidad Austral-Editorial Kultrun, Valdivia.

Hayden, B. 1998. Practical and prestige technologies: The evolution of material systems. Journal of Archaeological Method and Theory 5 (1):3-55.

Ingold, T. 2012. Toward an ecology of materials. Annual Review of Anthropology 41:427-442. 
Joyce, R. 2005. Archaeology of the body. Annual Review of Anthropology 34:139-158.

Kopytoff, I. 1991. La biografía cultural de las cosas. La mecantilización. En La Vida Social de las Cosas: Perspectiva Cultural de las Mercancías, editado por A. Appadurai, pp. 89124. Consejo Nacional para la Cultura y las Artes, México DF.

Lazzari, M. 1999. Distancia, espacio y negociaciones tensas: el intercambio de objetos en arqueología. En Sed non Satiata. Teoría Social en la Arqueología Latinoamericana Contemporanea editado por A. Zarankin y F.A. Acuto, pp. 117-151. Ediciones del Tridente, Buenos Aires.

Lazzari, M. 2005. The texture of things: objects, people, and landscape in northwest Argentina (First millenium A.D.). En Archaeologies of Materiality, editado por L. Meskell, pp. 126161. Blackwell Publishing, Malden.

Llagostera, A. 1996. San Pedro de Atacama: Nodo de Complementariedad Reticular. En La Integración Sur Andina Cinco Siglos Después, editado por X. Albó, M. I. Arratia, Jorge Hidalgo, Lautaro Núñez, Agustín Llagostera, M. I. Remy y B. Reresz, pp. 17-42. Centro de Estudios Regionales Andinos "Bartolomé de Las Casas", Cusco.

Malinowski, B. 1986. Los Argonautas del Pacífico Occidental. Un Estudio sobre Comercio y Aventura entre los Indígenas de los Archipiélagos de la Nueva Guinea Melanésica. Planeta D'Agostini, Barcelona.

Marx, K. 1975. El capital, crítica de la política económica, Tomo I. La Producción del Capital. Siglo XXI, Buenos Aires.

Mauss, M. 1973. Techniques of the body. Economy and Society 2:70-88.

Mauss, M. 1979. Ensayo sobre los dones. Motivo y forma del cambio en las sociedades primitivas. En Sociología y Antropología, pp. 155-258. Editorial Tecnos, Madrid.

McRostie, V. 2014. Arboricultura y Silvopastoralismo en el período Formativo (1.400 ac-500 dc) de la cuenca del Salar de Atacama. Chungara Revista de Antropología Chilena 46 (4):543-557.

Miller, D. 2005. Materiality: An Introduction. En Materiality, editado por D. Miller, pp. 1-49. Duke University Press, Durham.

Mayer, E. 1982. Un carnero por un saco de papas: aspectos del trueque en la zona de Chaupiwaranga, Pasco. Nueva Antropología. Revista de Ciencias Sociales 19:81-96.

Murra, J.V. 1972. El "control vertical" de un máximo de pisos ecológicos en la economia de las sociedades Andinas. En Visita de la Provincia de Léon de Huánuco en 1562 (Vol. I), editado por I. Ortíz de Zuñiga. Universidad Nacional Hermilio Valdizán, Huánuco.

Murra, J. 1975. Formaciones Económicas y Políticas en el Mundo Andino. Instituto de Estudios peruanos, Lima.

Murra, J.V. 2002. El tráfico de mullu en la costa del Pacífico. En El Mundo Andino, Población, Medio Ambiente y Economía pp. 171-178. Instituto de Estudios Peruanos/Pontificia Universidad Católica del Perú, Lima.

Nielsen, A. 2013. Circulating objects and the constitution of south Andean society (500 BC-AD 1550). En Merchants, Markets, and Exchange in the Pre-columbian World, editado por J. Pillsbury J. y M. Pye, pp. 389-418. Dumbarton Oaks, Washington DC.

Núñez, L., I. Cartajena, C. Carrasco y P. de Souza 2005. El templete de Tulán y sus relaciones formativas panandinas
(Norte de Chile). Bulletin de l'Institut Français d'Etudes Andines 34 (3):299-320.

Núñez, L., I. Cartajena, C. Carrasco y P. De Souza 2006a. El templete Tulán de la Puna de Atacama: emergencia de complejidad ritual durante el Formativo Temprano (norte de Chile). Latin American Antiquity 17 (4):445-473.

Núñez, L., I. Cartajena, C. Carrasco, P. De Souza y M. Grosjean 2006b. Emergencia de comunidades pastoralistas formativas en el sureste de la Puna de Atacama. Estudios Atacameños 32:93-117.

Núñez, L., I. Cartajena, C. Carrasco, P. López, P. De Souza, F. Rivera y B. Santander 2017. Presencia de un centro ceremonial formativo en la circumpuna de Atacama. Chungara Revista de Antropología Chilena 49 (1):3-33.

Núñez, L. y T. Dillehay 1995. Movilidad Giratoria, Armonía Social y Desarrollo en los Andes Meridionales: Patrones de Tráfico e Interacción Económica. Universidad del Católica del Norte, Antofagasta.

Olsen, B. 2003. Material culture after text: Re-membering things. Norwegian Archaeological Review 36 (2):87-104

Pastor, S., S. Gordillo y L. Tissera 2017. Objetos y paisajes multisensoriales del Holoceno tardío inicial en el centro de Argentina (ca. 3900 años AP): Acerca de un contexto arqueomalacológico de las Sierras de Córdoba. Intersecciones en Antropología 18 (3):317-327.

Peregrine, P. 1991. Some political aspects of craft specialization. World Archaeology 23 (1):1-11.

Pimentel, G. 2013. Redes Viales Prehispánicas en el Desierto de Atacama: Viajeros, Movilidad e Intercambio. Tesis para optar al grado de doctor. Universidad Católica del NorteUniversidad de Tarapacá, San Pedro de Atacama-Arica.

Pimentel, G., C. Rees, P. De Souza y L. Arancibia 2011. Viajeros costeros y caravaneros. Dos estrategias de movilidad en el Periodo Formativo del Desierto de Atacama, Chile. En En Ruta. Arqueología, Historia y Etnografía del Tráfico Sur Andino, editado por L. Núñez y A. Nielsen, pp. 43-82. Editorial Brujas, Córdoba.

Platt, T. 1987. Entre ch'axwa y muxsa. Para una historia del pensamiento político andino. En Tres Reflexiones sobre el Mundo Andino, editado por T. Bouysse-Cassagne, O. Harris, T. Platt y V. Cereceda, pp. 61-132. Hisbol, La Paz.

Pollard, G. 1971. Cultural change and adaptation in the central Atacama Desert of Northern Chile. Nawpa Pacha: Journal of Andean Archaeology 9:41-64.

Rees, C. 1999. Elaboración, distribución y consumo de cuentas de malaquita y crisocola durante el período Formativo en la vega de Turi y sus inmediaciones, subregión del río Salado, norte de Chile. En Los Tres Reinos; Prácticas de Recolección en el Cono Sur de América, editado por C. Aschero, A. Korstanje y R. Vuoto, pp. 85-98. Instituto de Arqueología y Museo, Universidad Nacional de Tucumán, Tucumán.

Salazar, D., H. Salinas, V. McRostie, R. Labarca y G. Vega 2010. Cerro Turquesa: Diez siglos de producción minera en el extremo norte de Chile. Actas del XVII Congreso Nacional de Arqueología Chilena Vol. 2, pp. 1085-1097.

Salazar-Soler, C. 1992. Encuentro de dos mundos: Las creencias acerca de la generación y explotación de los metales en las minas andinas del siglo XVI al XVIII. Etnicidad, Economía y Simbolismo en Los Andes. II Congreso Internacional de Etnohistoria, Coroico, editado por S. Arze, R. Barragan, L. Escobari y X. Medinacelli, pp. 237-254). Hisbol/IFEA/SBHAsur, Lima. 
Santander, B, M. Valenzuela, P. López, I. Cartajena y L. Núñez 2016. Tejiendo en el Formativo Temprano. Artefactos óseos y el uso de fibras animales en Tulan-54, Norte de Chile. Conferencia III Encuentro Latinoamericano de Zooarqueología. Aracajú, Sergipe.

Santoro, C., D. Osorio, P. Ugalde, M. Sepúlveda, I. Cartajena, V. Standen, E. Gayó, A. Maldonado, M. Rivadeneira, C. Latorre, B. Arriaza, F. Rothhammer, P. De Souza, C. Carrasco y L. Núñez 2016. Cazadores, recolectores y pescadores arcaicos del Desierto de Atacama. Entre el Pacífico y los Andes, norte de Chile (ca. 10.000 a 3.700 años a.p.). En Prehistoria en Chile: desde sus Primeros Habitantes hasta los Incas, editado por F. Falabella, M. Uribe, L. Sanhueza, C. Aldunate y J. Hidalgo, pp. 117-180. Editorial Universitaria, Santiago.

Sahlins, M. 1983a. El espíritu del don. En Economía de la Edad de Piedra. $2^{a}$ edición en español, pp. 167-201. Akal, Madrid.

Sahlins, M. 1983b. Sobre la sociología del intercambio primitivo. En Economía de la Edad de Piedra. $2^{\text {a }}$ edición en español, pp. 203-295. Akal, Madrid.

Sinclaire, C. 2004. Prehistoria del período Formativo en la cuenca alta del río Salado (región del Loa Superior). Chungara Revista de Antropología Chilena 36 (2):619-639.

Sinclaire, C, M. Uribe, P. Ayala y J. González 1997. La alfarería del período Formativo en la Región del Loa Superior: sistematización y tipología. Actas del XIV Congreso Nacional de Arqueología Chilena. Tomo II, pp. 285-314. Contribuciones Arqueológicas 5. Museo Regional, Copiapó.

Soto, C. 2006. Cuentas de Collar en la Quebrada de Tulán, Características y diferencia entre los periodos Arcaico y Formativo. Informe de Práctica Profesional. Departamento de Antropología, Universidad de Chile, Santiago.

Soto, C. 2009. Desde el Mar y la Selva: Usos Simbólicos de los Restos Malacológicos en la Fase Tilocalar, Quebrada Tulan (3500-2500 AP). Memoria para optar al título de Arqueóloga. Departamento de Antropología, Facultad de Ciencias Sociales. Universidad de Chile, Santiago.

Soto, C. 2010. Sobre las identidades en el Alfarero Temprano de Chile Central: un acercamiento desde los objetos ornamentales. Werken 12:77-90.

Soto, C. 2015. Amuletos en el Cuerpo, Ofrenda a las Huacas: Reflexiones sobre Cultura Material y Visual desde los Objetos Perforados y sus Usos en el Periodo Formativo (1500 AC-800
DC) del Desierto de Atacama (II Región, Chile). Tesis para optar al grado de Magister en Artes, mención Teoría e Historia del Arte. Facultad de Artes, Universidad de Chile, Santiago.

Soto, C. y X. Power 2013. Argopecten purpuratus en la Arqueomalacología de Taltal. Taltalia 5-6:21-35.

Soto, C., X. Power y B. Ballester 2018. Objetos perforados en el Desierto de Atacama: surgimiento, proliferación y difusión de una tecnología de producción de objetos simbólicos (6000-3500 Cal. AP). Boletín Museo Chileno de Arte Precolombino 23 (1):51-69.

Stanish, C. y L. Coben 2013. Barter markets in the pre-hispanic Andes. En Merchants, Markets, and Exchange in the Precolumbian World, editado por J. Pillsbury J. y M. Pye, pp. 419434. Dumbarton Oaks, Washington DC.

Téllez, F. 1997. Sthrophochelius Oblongus Müll: Restos de fauna malacológica tropical en contextos funerarios de San Pedro de Atacama: Norte de Chile (Informe preliminar). Estudios Atacameños 14:95-120.

Torres-Rouff, C., G. Pimentel y M. Ugarte 2012. ¿Quiénes viajaban?: Investigando la muerte de viajeros prehispánicos en el Desierto de Atacama (CA. 800 AC-1536 DC). Estudios Atacameños 43:167-186.

Thomas, C., M.A. Benavente, I. Cartajena y G. Serracino 1995. Topater, un cementerio temprano: una aproximación simbólica. Hombre y Desierto 9:159-169.

Thomas, N. 1991. Entangled Objects. Exchange, Material Culture and Colonialism in the Pacific. Harvard University Press, Cambridge.

Uribe, M. 2006. Sobre cerámica, su origen y complejidad social en los Andes del Desierto de Atacama, norte de Chile. En Esferas de Interacción Prehispánicas y Fronteras Nacionales Modernas: Los Andes Sur Centrales, editado por H. Lechtman, pp. 449-502. Instituto de Estudios Peruanos, Lima.

Vidal, A. 2007. Patrones de Uso de los Recursos Vegetales Durante el Periodo Formativo (1000aC-500dC) en San Pedro de Atacama: Oasis y Quebradas. Memoria para optar al título de Arqueóloga. Departamento de Antropología, Facultad de Ciencias Sociales. Universidad de Chile, Santiago.

Waskul, D. y P. Vannini 2006. Introduction: The Body in Symbolic Interaction. En Body/embodiment: Symbolic Interaction and the Sociology of the Body, editado por D. Waskul y P. Vannini, pp. 1-18. Ashgate, Wiltshire. 
